
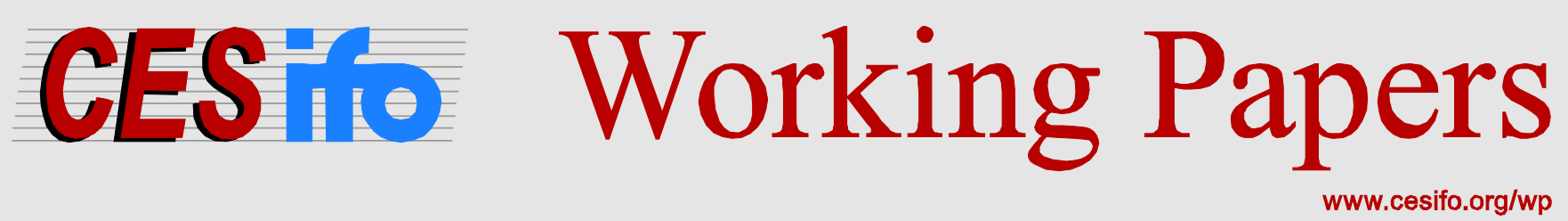

\title{
Commitment vs. Discretion in Climate and Energy Policy
}

\author{
Florian Habermacher \\ Paul Lehmann
}

\author{
CESIFO WORKING PAPER NO. 6355 \\ CATEGORY 10: ENERGY AND CliMATE ECONOMICS \\ FEBRUARY 2017
}

An electronic version of the paper may be downloaded

- from the SSRN website:

- from the RePEc website:

- from the CESifo website:

wWw.SSRN.com

www.RePEc.org

www.CESifo-group.org/wp 


\title{
Commitment vs. Discretion in Climate and Energy Policy
}

\begin{abstract}
To decarbonize the power sector policy-makers need to commit to long-term credible rules for climate and energy policy. Otherwise, time-inconsistent policy-making will impair investments into low-carbon technologies. However, the future benefits and costs of decarbonization are subject to substantial uncertainties. Thus, there may also be societal gains from allowing policymakers the discretion to adjust the policies as new information becomes available. We examine how this trade-off between policy commitment and discretion affects the optimal intertemporal design of policies to support the deployment of renewable energy sources. Using a dynamic partial equilibrium model of the power sector, we show that commitment to state-contingent renewable subsidies outperforms both unconditional commitment and discretion. The choice between the practically more feasible approaches of unconditional commitment and discretion is analytically ambiguous. A numerical illustration with naïve assumptions suggests that policy discretion may outperform unconditional commitment in terms of welfare. However, extensions to more realistic cases where only a limited fraction of climate uncertainty resolves, where future policy-makers have own agendas, or with risk-averse investors show commitment as favorable.
\end{abstract}

JEL-Codes: H230, Q420, Q480, Q540, Q580.

Keywords: climate change, public policy, subsidies, renewable energy, time inconsistency, uncertainty, commitment, hold-up.

Florian Habermacher

Swiss Institute for International Economics and Helmholtz Centre for Environmental Research

Applied Economic Research

University of St. Gallen

St. Gallen / Switzerland

florian.habermacher@unisg.ch
Paul Lehmann

- UFZ, Department of Economics

Leipzig / Germany

paul.lehmann@ufz.de

February 9, 2017

Florian Habermacher's independent research was supported by Aurora Energy Research. Paul Lehmann's research has been funded by Deutsche Forschungsgemeinschaft (DFG) under Grant LE 3746/1-1. We are very grateful for valuable comments and suggestions made by Erik Gawel, Reyer Gerlagh, Cameron Hepburn and Alex Teytelboym. Our paper also benefited from discussions during research seminars held at the Institute for New Economic Thinking at the University of Oxford and the Department of Economics at the Helmholtz Centre for Environmental Research - UFZ. 


\section{Introduction}

It is a long-standing paradigm that economic policy should commit to long-term credible rules for private economic activities to promote economic development. Already Kydland and Prescott (1977) emphasized in their seminal paper that the discretion to adjust a policy over time would reduce welfare because time-inconsistent policy-making distorts the decisions of forward-looking rational agents. However, it has subsequently been emphasized that discretion may generate economic benefits if policies can be adjusted over time to better reflect initially uncertain future policy costs and benefits, for example in the presence of unforeseen events and shocks (Fisher, 1977; Lohmann, 1992; Rogoff, 1985). Thus, there is a fundamental trade-off between policy commitment and discretion. In this paper we will argue that understanding this trade-off and its implications for optimal policy-making is highly relevant for climate policy. We will shed particular light on policies promoting power generation from renewable energy sources (RES). Such schemes are a major pillar of climate policy worldwide and have exhibited very heterogeneous patterns of commitment and discretion. Our findings will also have implications for more general instruments of climate policy, such as carbon pricing.

Though usually considered only a second- or third-best policy response to market failures, a number of plausible economic reasons have been brought forward why RES support schemes may need to complement (imperfect) carbon pricing to mitigate climate change (Acemoglu et al., 2012; Aghion et al., 2009; Fischer and Newell, 2008; Goulder and Schneider, 1999; Kalkuhl et al., 2012; Palmer and Burtraw, 2005) ${ }^{1}$. RES support schemes have been implemented in more than 110 countries (REN21, 2016). Subsidies distributed to private actors through these schemes have grown to an estimated $\$ 112$ billion worldwide in 2014 (IEA, 2015). Strikingly, existing RES support schemes have followed quite diverse pathways of commitment and, as the evolution of feed-in tariffs for newly installed onshore wind power plants in selected European countries illustrates (Figure 1). Against this background, it is surprising that the discussion on the trade-off between RES policy commitment and discretion has received little attention in the economic literature so far. ${ }^{2}$

\footnotetext{
${ }^{1}$ Reviews of rationales for combining RES policies with other climate policy instruments, such as emissions trading, are provided by Bennear and Stavins (2007), Fischer and Preonas (2010) and Lehmann and Gawel (2013). 2 Brunner et al. (2012), Finon and Perez (2007), Hepburn (2006) and Purkus et al. (2015) highlight this trade-off. They do not carry out a formal or empirical analysis.
} 
Figure 1: Evolution of feed-in tariffs for newly installed onshore wind power in selected European countries (year of introduction = 100). Source: Own figure based on data from www.res-legal.eu (accessed 20/10/2016)

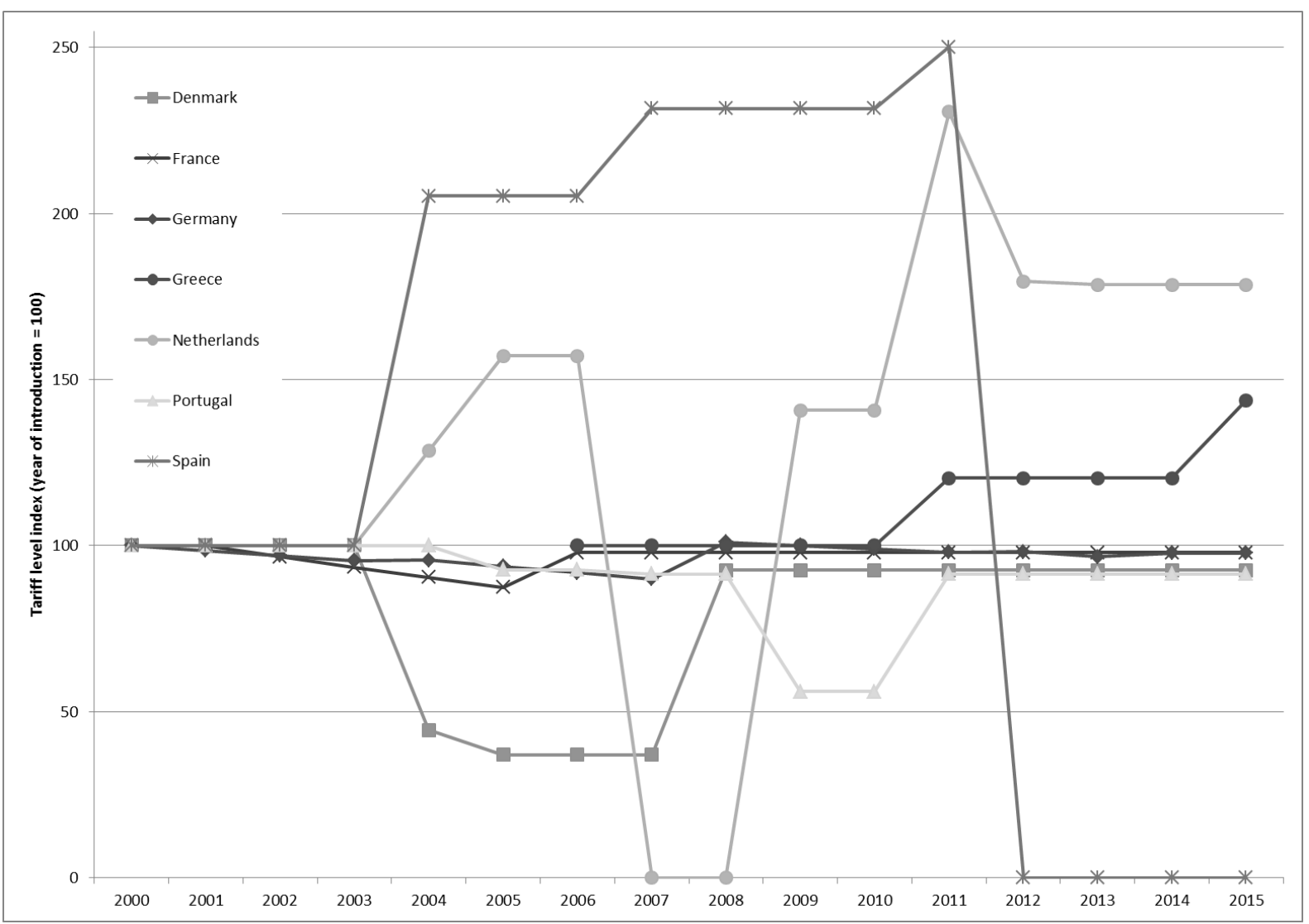

Why may the choice between RES policy commitment and discretion be ambiguous? On the one hand, the discretion to adjust RES policies over time is likely to result in time-inconsistent policy-making. Policy-makers introduce RES policies to promote investments into research and development, manufacturing and deployment of RES technologies, and to generate the corresponding benefits of mitigating climate change and other environmental impacts from fossil and nuclear power generation. Many of these investments are large-scale, long-lived and largely irreversible - as for most energyrelated investments (Neuhoff, 2005). Consequently, RES investments result in path dependencies with significant levels of sunk costs. Once investments are locked in, policy-makers have an incentive to reduce RES support to minimize the social burden and the political popularity costs of RES policies. These arise because surcharges on the power price or general taxes need to be levied to fund RES policies. The expectation that policies may be adjusted in the future can lead to suboptimal investment decisions of private actors today: Firms foreseeing lower support in the future will have an incentive to reduce RES investments (the hold-up problem, see, e.g., Hepburn (2006)). In this respect, the high degree of discretion which characterizes many RES support schemes (see Figure 1) may be viewed critically. Disincentivizing investments, a lacking commitment to a long-term RES policy path may impair the decarbonization of the power sector and the attainment of ambitious emission reduction targets. 
On the other hand, the future benefits and costs of RES policies are equally subject to large uncertainties. These uncertainties imply that RES support levels chosen ex ante may turn out to be inefficiently low or high ex post when compared to actual costs and benefits at a future time. Therefore, welfare may be increased if policy makers have the discretion to adjust RES policies as new knowledge becomes available - which has been pointed out for industry policy in general (Rodrik, 2014) and innovation policy in particular (Aghion et al., 2009; Foxon and Pearson, 2008). Uncertainties are related to, inter alia, the future development of technology costs or the external environmental benefits and system integration costs arising with increasing levels of RES deployment (Purkus et al. (2015)). Empirical assessments show that the uncertainties surrounding the future costs of RES deployment are substantial, e.g., due to large variations in observed learning rates (Rubin et al., 2015). Furthermore, the social cost of carbon, and therewith the benefit of emissions avoided by RES deployment, remains highly speculative (Greenstone et al., 2013; Tol, 2009).

Thus, the potential trade-off between commitment and discretion is a highly relevant issue for the optimal design of RES policies. In a similar way, this trade-off may also play out for climate policy in general, notably for carbon taxes or emissions trading schemes. Commitment may prevent policymakers from exploiting technological path dependency opportunistically, e.g. to reduce the burden of carbon pricing on household and industries. At the same time, climate policy will always be subject to uncertain benefits and costs, justifying a certain adjustments over time.

Our study addresses the fundamental question under which assumptions policy-makers should be committed to a long-term RES policy path, or instead be allowed adjusting it in the future. To analyze this trade-off, we develop a dynamic partial equilibrium model for the power sector. Within this framework, we examine the simplest case of RES support: A subsidy granted for RES generation in addition to the electricity price. Analyzing RES subsidies is a useful proxy for most existing RES support schemes, ranging from feed-in and premium tariffs to quotas (or renewable portfolio standards) with tradable green certificates (see, e.g., Kitzing et al., 2012). Moreover, this approach more generally also provides more insights for carbon pricing, which changes the relative cost of fuel-based and RES technologies, as RES subsidies do. In either case, the social planner directly or indirectly commits (or not) to creating an additional revenue stream for RES-E investors. We look at three selected policy scenarios which vary in when and how the social planner decides on the level of a subsidy paid for RES deployment in the future:

(1) unconditional commitment to a long-run RES subsidy path, i.e. the subsidy level decided upon today is not adjusted in the future, even if knowledge gained in the future suggests it is inefficient,

(2) rule-based commitment to a set of state-contingent RES subsidy levels, which explicitly relate possible future states of the world (e.g. high and low benefits or costs) to corresponding subsidy levels, and 
(3) discretion to adjust the long-run RES subsidy path, i.e. the subsidy can be freely adapted to the optimal level in the future, which may differ from a level otherwise committed to, because of new knowledge on costs or benefits as well as time-inconsistent policy-making.

We find that rule-based commitment generally outperforms both unconditional commitment as well as discretion. Yet, as perfect rule-based commitment itself seems in many cases impractical, given difficulties to contractually specify and monitor possible states of the world, the comparison of unconditional commitment and discretion is more relevant. We show that the choice between both approaches is analytically ambiguous if the benefits of RES deployment in terms of avoided social cost of carbon are uncertain. However, a numerical application for plausible ranges of the social cost of carbon provides clearer results. In a more naïve version of the framework, discretion, in the sense of an optimal, forward-looking adaptation of policies to new information, seems superior to unconditional commitment for reasonable parameter values, even if only marginally so. The relative advantage of discretion seems to vanish once we account for (a) climate uncertainty resolving only slowly over time, (b) policy-makers deviating arbitrarily from inter-temporally optimal policy levels, and (c) risk-averse investors.. We further analyze how the policy choice is affected by uncertainty in RES deployment costs (instead of benefits). In this case, commitment is strictly superior (inferior) to discretion as long as the subsidy is meant to internalize an external benefit (attain a politically set RES deployment target). Overall, our results therefore suggest that, while pertinent economic reasons for discretionary RES policy-making exist, the second-best policy approach is still in many cases to commit to a longer term RES subsidy path.

The paper reconciles two major strands of environmental economic research. A first, broad strand of literature examines how optimal environmental policy-making is affected by time inconsistency. Available studies show that this problem may be reduced by favoring price over quantity approaches (Baldursson and von der Fehr, 2008; Biglaiser et al., 1995), by earmarking tax revenues (Marsiliani and Renström, 2000), by combining carbon pricing with complementary technology policies (Abrego and Perroni, 2002; Ulph and Ulph, 2013), or by delegating climate policy-making to an independent carbon bank (Helm et al., 2003, 2004; Levine et al., 2005). However, these studies largely ignore the potential benefits of discretion if costs and benefits of environmental policy are uncertain, assuming that full commitment to an intertemporal environmental policy path would always be the optimal solution.

A second strand of literature discusses policy-making under uncertainty about costs and benefits of pollution control. It is shown that uncertainty affects the optimal choice and combination of policy instruments as well as their optimal intensity (e.g., Jacoby and Ellerman, 2004; Pizer, 2002; Roberts and Spence, 1976; Stavins, 1996; Weitzman, 1974). Moreover, uncertainty may also determine the optimal timing of environmental policy if the latter induces irreversible investments (e.g., Pindyck, 2000, 2002). However, these analyses ignore questions arising if uncertainty combines with problems of timeinconsistent policy-making, which is the focus of the present study. 
The remainder of the paper is organized as follows. Section two introduces the basic model set-up as well as the deterministic benchmark case. Section three provides the analytical discussion and numerical illustration of the choice between RES policy commitment and discretion when benefits are uncertain. Section four replicates this analysis for the case of uncertain costs of RES deployment. Section five provides a discussion of our analytical and numerical results, and section six concludes.

\section{Model and deterministic benchmark case}

\subsection{Model}

We consider a simple dynamic partial equilibrium model with three periods $t=[1,2,3]$ and per-period discounting at factor $\delta$. In the first two periods, $t=[1,2]$, a representative firm can make an investment to install RES plants with capacity $x_{t}$ for power generation. Plants installed are in operation for two periods. We include the third period to generate symmetric pay-off streams for investments made in the first and second period. For simplicity, we assume that the conversion factor from capacity to power is constant, and we normalize it to unity, i.e., RES power generation corresponds to available capacity in that period. Consequently, period-specific total power generation $q_{t}$ is given as:

$$
q_{1}=x_{1} \quad q_{2}=x_{1}+x_{2} \quad q_{3}=x_{2}
$$

The power market is assumed to clear, and consumer benefit increases linearly in power generation (or consumption):

$$
V_{t}\left(q_{t}\right)=v q_{t}
$$

Correspondingly, the wholesale market price for power is constant and given by ${ }^{3}$ :

$$
p_{t}=v
$$

To capture the very low running costs of typical non-thermal RES, generation costs are assumed to be limited to sunk, convex investment costs:

$$
C_{t}\left(x_{t}\right)=\frac{c_{t}}{2} x_{t}^{2}
$$

Convexity represents the fact that some inputs to RES deployment - such as windy (or sunny) and politically accepted deployment sites, trained labor, investment capital, or construction material become scarcer as more RES plants are installed in a single period (i.e., the RES supply curve is upwardsloping for a given period, see, e.g. Denholm and Margolis (2008) and Kline et al. (2008)). Moreover, convexity in costs can also be seen as a proxy for the fact that the market value of RES is falling with

\footnotetext{
${ }^{3}$ An alternative, compatible interpretation is that consumers have decreasing marginal utility from power consumption and that RES are an alternative to conventional power which has constant returns to scale at unitary cost of $v$.
} 
higher penetration rates (e.g., Hirth, 2013). The absence of variable generation costs implies that power from investments made in period 1 (or 2) can be generated in period 2 (or 3) at zero cost. This creates a path-dependency for generation in period $t+1$ based on sunk RES investment in period $t$. At the beginning of period 1 , the cost parameter $c_{t}$ is known with certainty for period 1 . It may be uncertain and depend on the future state $i \epsilon\{H, L\}$ for period 2: It is $c_{2 H}$ in a high-cost state occurring with probability $\beta$, and $c_{2 L}$ in a low-cost state occurring with probability $(1-\beta)$. The corresponding expectation value $E\left[c_{2}\right]$ and variance $\sigma_{c}^{2}$ are:

$$
\begin{aligned}
& E\left[c_{2}\right]=\beta c_{2 H}+(1-\beta) c_{2 L} \\
& \sigma_{c}^{2}=\left(c_{2 H}-c_{2 L}\right)^{2} \beta(1-\beta)
\end{aligned}
$$

Consequently, the cost function for period 2 is state-contingent in the presence of uncertainty, i.e. $C_{2 i}\left(x_{2}\right)=c_{2 i} x_{2}^{2} / 2$. Uncertainty dissolves at the beginning of period 2 . The (expected) cost parameter may decline over time, i.e., $c_{1}>E\left[c_{2}\right]$, due to exogenous technological progress.

In the main, Pigouvian version of our framework, we assume RES generation to produce an external benefit $B_{t}\left(q_{t}\right)$, with

$$
B_{t}\left(q_{t}\right)=b_{t} q_{t}
$$

The benefit parameter $b_{t}$ may vary between period 1 and 2 but for simplicity is assumed to be identical in period 2 and 3. At the beginning of period 1, the benefit parameter for period 1 is known. The parameter for period 2 and 3 may be uncertain at this point and depend on the future state $i \epsilon\{H, L\}$ : It is $b_{2 H}$ in a high-benefit state $H$ occurring with probability $\alpha$, and $b_{2 L}$ in a low-benefit state occurring with probability $(1-\alpha)$. Correspondingly, the expectation value $E\left[b_{2}\right]$ and the variance $\sigma_{b}^{2}$ are:

$$
\begin{aligned}
& E\left[b_{2}\right]=\alpha b_{2 H}+(1-\alpha) b_{2 L} \\
& \sigma_{b}^{2}=\left(b_{2 H}-b_{2 L}\right)^{2} \alpha(1-\alpha)
\end{aligned}
$$

In the presence of uncertainty the benefit function for period 2 and 3 can therefore be rewritten as $B_{t i}\left(q_{t}\right)=b_{2 i} q_{t}$. Again, uncertainty about the actual state of the benefit is assumed to vanish at the beginning of period 2 as more information becomes available. We eventually reconsider this strong assumption in an extension accounting for the fact that only a small part of climate uncertainty will resolve within a decade or so.

In a variation of our framework, we consider the standard-price case where an externally given political target for RES deployment $\bar{T}$ is the dominant driver for RES support, rather than the explicit concern for environmental benefits.

To internalize the external benefit - or to reach a given policy target in the standard-price case - the social planner introduces a subsidy $s_{t}$ in all three periods, which is paid per unit of electricity generated. 
More generally, this subsidy could also be interpreted as the cost advantage implied by a carbon tax. The subsidy may vary between period 1 and 2, but remains unchanged between 2 and 3, i.e., $s_{2}$ applies in period 3 as well. The subsidy brings about a social deadweight loss $L_{t}\left(s_{t}, q_{t}\right)$ with

$$
L_{t}\left(s_{t}, q_{t}\right)=l s_{t} q_{t}
$$

This deadweight loss can be seen as an expression of the welfare cost from distortionary taxes levied to fund the subsidy, or the excess burden on power consumers arising if the subsidy is funded by a surcharge on the electricity price. ${ }^{4}$ More generally, this loss may represent any other social or political overhead cost related to covering the expenditure for the subsidy, e.g., losses in political popularity.

When deciding on the subsidy rate the social planner aims to maximize social welfare, which is given as the present-discounted private and external RES consumption benefits, net of investment costs and deadweight loss. While the external benefit or the explicit RES target incentivizes the policy-maker to implement a subsidy, the deadweight loss induces her to restrict the cost of the subsidy scheme. This will be the decisive trade-off playing out in the subsequent policy analyses.

Using this model setup, we analyze three sets of policy scenarios which vary in when and how the social planner decides on the subsidy applicable for periods 2 and 3 :

- Unconditional commitment (U): Commitment in period 1 to a fixed subsidy rate $s_{2}$.

- Rule-based commitment (R): Commitment in period 1 to a state-contingent subsidy rule, setting for each state $i$ a corresponding subsidy rate $s_{2 i}$, chosen in line with the uncertain benefit or cost parameter, $b_{2 i}$ or $c_{2 i}$ respectively.

- Discretion (Non-commitment N): Setting a subsidy rate $s_{2 i}$ in period 2 after learning about the firm's investment in period 1 and the actual state of the uncertain parameter in period 2.

We first examine these options in a deterministic environment (section 2.2). This benchmark case illustrates how time-inconsistent policy-making plays out if external benefits and investment costs in period 2 are perfectly known. Obviously, rule-based commitment is obsolete (or identical to unconditional commitment) in this setting. Subsequently, we analyze optimal RES policy-making in a setting in which the external benefit parameter $b$ is uncertain (section 3). For this case, we distinguish four sub-cases: (a) a naïve setting with simplistic assumptions about the world and three more realistic settings assuming that (b) uncertainty dissolves only slowly over time, (c) policy-makers deviate arbitrarily from the time-inconsistent optimal subsidy level in period 2, or (d) investors are risk averse. Finally, the case with an uncertain investment cost parameter $c$ is discussed (section 4). For most of these policy scenarios, we consider a Pigouvian setting, in which the subsidy is meant to internalize

\footnotetext{
${ }^{4}$ In our simple partial equilibrium model with only renewable power generation the surcharge on the power price to fund the subsidy would be equal to $s_{t}$.
} 
some external benefit from RES generation. In addition, we also shed light on a standard-price-setting, in which the subsidy is meant to address a politically set RES deployment target. We include this policy approach because it reflects ubiquitous policy practice, for example, in the EU, where explicit RES explicit targets have been set for 2020 and 2030 (European Commission, 2014). This policy approach is neither relevant in a deterministic setting (because the fixed target precludes discretionary policymaking, see our discussion in section 4) nor in an environment where only external benefits are uncertain (as the target is by definition set independently of actual benefits). However, we will show that it may affect the choice between commitment and discretion when the cost parameter is uncertain.

Consequently, we evaluate the policy scenarios summarized in Table 1.

Table 1: Policy scenarios evaluated

\begin{tabular}{|c|c|c|c|c|}
\hline & & $\begin{array}{l}\text { Unconditional } \\
\text { commitment to a } \\
\text { single period-2 } \\
\text { subsidy (C) }\end{array}$ & $\begin{array}{l}\text { Rule-based } \\
\text { commitment to a } \\
\text { state-conditional } \\
\text { period-2 subsidy } \\
\text { (R) }\end{array}$ & $\begin{array}{l}\text { Discretion to } \\
\text { choose period-2 } \\
\text { subsidy }(\mathrm{N})\end{array}$ \\
\hline $\begin{array}{l}\text { Deterministic } \\
\text { environment } \\
\text { (D) } \\
\text { (section 2.2) }\end{array}$ & \multirow{3}{*}{$\begin{array}{l}\text { RES subsidy to } \\
\text { internalize } \\
\text { external benefit } \\
\text { (Pigouvian } \\
\text { approach) }\end{array}$} & DC & n.a. & DN \\
\hline $\begin{array}{l}\text { Uncertain } \\
\text { external } \\
\text { benefits (U) } \\
\text { (section 3) }\end{array}$ & & $\mathrm{UC}$ & UR & UN \\
\hline \multirow{2}{*}{$\begin{array}{l}\text { Uncertain } \\
\text { investment } \\
\text { costs (UK) } \\
\text { (section 4) }\end{array}$} & & UKC & UKR & UKN \\
\hline & $\begin{array}{l}\text { RES subsidy to } \\
\text { attain fixed target } \\
\text { (F) (standard- } \\
\text { price approach) }\end{array}$ & UKFC & UKFR & UKFN \\
\hline
\end{tabular}

2.2 Benchmark case: Optimal RES support in a deterministic environment (D)

This section examines RES policy-making in a setting where future benefits and costs are known. Consequently, we only compare unconditional commitment to full discretion. This comparison serves to illustrate how the basic mechanism of time-inconsistent policy-making plays out in the absence of 
uncertainty. The representative firm's optimization problem is to choose investment levels $x_{1}$ and $x_{2}$ to maximize profit $\pi$ over all periods:

$$
\max _{x_{1}, x_{2}} \pi^{D}=p_{1} q_{1}-C_{1}\left(x_{1}\right)+s_{1} q_{1}+\delta\left[p_{2} q_{2}-C_{2}\left(x_{2}\right)+s_{2} q_{2}\right]+\delta^{2}\left(p_{3} q_{3}+s_{2} q_{3}\right)
$$

where superscript $D$ denominates the policy scenario.

The first-order conditions for profit-maximizing investment can be derived from (1) (here and in the remainder we will immediately apply $p_{t}=v$ ),

$$
\begin{gathered}
x_{1}^{D}=\frac{s_{1}+v+\delta\left(s_{2}+v\right)}{c_{1}} \\
x_{2}^{D}=\frac{\left(s_{2}+v\right)(1+\delta)}{c_{2}},
\end{gathered}
$$

whose form can be readily understood: the quadratic investment cost means that the investment level (and thus the marginal investment cost) is proportional to the discounted sum over the plant lifetime of current and future period market value $v$ of the RES output augmented by the subsidy $s$, and inversely proportional to the cost factor $c$. With other words: free entry into the market means investments occur until the level at which RES investment projects just break-even in terms of net present value.

\subsubsection{Unconditional commitment $(D C)$}

The social planner faces the problem to choose subsidy rates $s_{1}$ and $s_{2}$ to maximize social welfare, taking firm reactions (2) and (3) into account, which is given as:

$$
\begin{gathered}
W^{D C}=V_{1}\left(q_{1}\right)-C_{1}\left(x_{1}\right)-L_{1}\left(s_{1}, q_{1}\right)+B_{1}\left(q_{1}\right)+\delta\left[V_{2}\left(q_{2}\right)-C_{2}\left(x_{2}\right)-L_{2}\left(s_{2}, q_{2}\right)+\right. \\
\left.B_{2}\left(q_{2}\right)\right]+\delta^{2}\left[V_{3}\left(q_{3}\right)-L_{3}\left(s_{2}, q_{3}\right)+B_{3}\left(q_{3}\right)\right],
\end{gathered}
$$

where superscript $D C$ denominates the policy scenario. If the planner can commit, the socially optimal subsidies are derived by inserting the firm's first-order conditions (2) and (3) into (4), deriving the firstorder conditions that maximize welfare with respect to $s_{1}$ and $s_{2}$, and solving the resulting equation system for $s_{1}$ and $s_{2}$ (optimal values are indicated by an asterisk):

$$
s_{t}^{D C *}=\frac{b_{t}-l v}{1+2 l}
$$

Thus, in line with the Pigouvian internalization rule, the optimal subsidy corresponds to the marginal external benefit adjusted for the marginal deadweight loss produced by the subsidy.

Substituting (5) into (2) and (3) yields the socially optimal investment levels in period 1 and 2:

$$
x_{1}^{D C *}=\frac{b_{1}+\delta b_{2}+(1+\delta)(1+l) v}{c_{1}(1+2 l)}
$$




$$
x_{2}^{D C *}=\frac{(1+\delta)\left(b_{2}+v(1+l)\right)}{c_{2}(1+2 l)}
$$

Substituting (5) and (6) into (4), we can derive welfare in the optimum:

$$
\begin{gathered}
W^{D C *}=\frac{1}{2 c_{1} c_{2}(1+2 l)}\left(b_{1}^{2} c_{2}+c_{1}\left(b_{2}+v(1+l)\right)^{2} \delta(1+\delta)^{2}+2 b_{1} c_{2}\left(b_{2} \delta+(1\right.\right. \\
\left.+l) v(1+\delta))+c_{2}\left(b_{2} \delta+(1+l) v(1+\delta)\right)^{2}\right)
\end{gathered}
$$

\subsubsection{Discretion $(D N)$}

In the full discretion scenario, the social planner and the representative firm play a sequential game with four stages. First, at the beginning of period 1 , the social planner announces a subsidy rate $s_{1}$. Second, the firm takes an investment decision for period 1 based on $s_{1}$ as well as the expectation of $s_{2}$. Third, at the beginning of period 2, the social planner sets $s_{2}$. Finally, the firm chooses investment for period 2 based on $s_{2}$. This game is solved by backward induction.

The planner's period 2 problem is that of choosing $s_{2}$ such as to maximize welfare $W_{2}^{D N}$ for a given $x_{1}$ and $s_{1}$ and firm reaction (3), where

$$
\begin{array}{r}
\max _{s_{2}} W_{2}^{D N}=V_{2}\left(q_{2}\right)-C_{2}\left(x_{2}\right)-L_{2}\left(s_{2}, q_{2}\right)+B_{2}\left(q_{2}\right) \\
+\delta\left[V_{3}\left(q_{3}\right)-L_{3}\left(s_{2}, q_{3}\right)+B_{3}\left(q_{3}\right)\right]
\end{array}
$$

Inserting the firm's reaction function (3) into (8) and deriving the first-order condition yields the social planner's choice of the period-2 subsidy as a function of period-1 investment:

$$
s_{2}^{D N}\left(x_{1}\right)=\frac{b_{2}(1+\delta)^{2}-l\left(v(1+\delta)^{2}+c_{2} x_{1}\right)}{(1+2 l)(1+\delta)^{2}}
$$

The rational firm will consider this policy choice when deciding on investment in period 1. Substituting (9) into the firm's first-order condition for period 1, given by (2), we find the firm's period-1 investment as a function of the period-1 subsidy:

$$
x_{1}^{D N}\left(s_{1}\right)=\frac{(1+\delta)^{2}\left(s_{1}+2 l s_{1}+b_{2} \delta+v(1+\delta+l(2+\delta))\right)}{c_{2} l \delta+c_{1}(1+2 l)(1+\delta)^{2}}
$$

Substituting (10) back into (9) yields the period-2 subsidy as a function of the period-1 subsidy:

$$
s_{2}^{D N}\left(s_{1}\right)=\frac{b_{2} c_{1}(1+\delta)^{2}-l\left(c_{1} v(1+\delta)^{2}+c_{2}\left(s_{1}+v+v \delta\right)\right)}{c_{2} l \delta+c_{1}(1+2 l)(1+\delta)^{2}}
$$

Substituting (11) back into (3) gives the firm's investment choice in period 2 as a function of the period1 subsidy:

$$
x_{2}^{D N}\left(s_{1}\right)=\frac{(1+\delta)\left(-c_{2} l\left(s_{1}+v\right)+b_{2} c_{1}(1+\delta)^{2}+c_{1}(1+l) v(1+\delta)^{2}\right)}{c_{2}\left(c_{2} l \delta+c_{1}(1+2 l)(1+\delta)^{2}\right)}
$$


These reaction functions are considered by the social planner when setting the optimal subsidy for period 1. Inserting (10)-(12) into (4) and deriving the first-order condition yields the optimal period-1 subsidy:

$$
\begin{aligned}
s_{1}^{D N *}=\frac{1}{(1+2 l) n_{1}} & \left(b_{1}(1+2 l)\left(c_{2} l \delta+c_{1}(1+2 l)(1+\delta)^{2}\right)\right. \\
& +l\left(-c_{1}(1+2 l)^{2} v(1+\delta)^{2}\right. \\
& \left.\left.+c_{2} \delta\left(b_{2}(1+l) \delta+v\left(1+\delta+l^{2} \delta+2 l(1+\delta)\right)\right)\right)\right)
\end{aligned}
$$

where $n_{1} \equiv\left(\mathrm{c}_{2} l^{2} \delta+\mathrm{c}_{1}(1+2 l)^{2}(1+\delta)^{2}\right)>0$.

Substituting (13) into (10)-(12), we can derive the optimal subsidy for period 2 as well as the corresponding investment levels in both periods:

$$
\begin{aligned}
s_{2}^{D N *}=\frac{1}{(1+2 l) n_{1}} & \left(b_{2}\left(-c_{2} l(1+l) \delta+c_{1}(1+2 l)^{2}(1+\delta)^{2}\right)\right. \\
- & l\left(b_{1}\left(c_{2}+2 c_{2} l\right)\right. \\
+ & \left.\left.v\left(c_{1}(1+2 l)^{2}(1+\delta)^{2}+c_{2}\left(1+\delta+3 l(1+\delta)+l^{2}(2+3 \delta)\right)\right)\right)\right) \\
x_{2}^{D N *}=\frac{1}{c_{2}(1+} & 2 l) n_{1}\left(( 1 + \delta ) \left(-b_{1} c_{2} l(1+2 l)\right.\right. \\
& +b_{2}\left(-c_{2} l(1+l) \delta+c_{1}(1+2 l)^{2}(1+\delta)^{2}\right) \\
& \left.\left.+(1+l) v\left(c_{1}(1+2 l)^{2}(1+\delta)^{2}-c_{2} l(1+\delta+l(2+\delta))\right)\right)\right)
\end{aligned}
$$

Substituting (13)-(15) into (4) gives the welfare in the optimum:

$$
\begin{aligned}
& W^{D N *}=\frac{1}{2 c_{2}(1+2 l) n_{1}}\left(( 1 + \delta ) ^ { 2 } \left(c_{2}\left(b_{1}+2 b_{1} l\right)^{2}\right.\right. \\
& +c_{1}(1+2 l)^{2}\left(b_{2}+v(1+l)\right)^{2} \delta(1+\delta)^{2} \\
& +2 b_{1} c_{2}(1+2 l)^{2}\left(b_{2} \delta+(1+l) v(1+\delta)\right) \\
& +c_{2}\left(b_{2}^{2}\left(1+4 l+5 l^{2}\right) \delta^{2}\right. \\
& +2 b_{2}(1+l) v \delta\left(1+\delta+4 l(1+\delta)+l^{2}(4+5 \delta)\right) \\
& \left.\left.\left.+(1+l)^{2} v^{2}\left((1+\delta)^{2}+4 l(1+\delta)^{2}+l^{2}\left(4+8 \delta+5 \delta^{2}\right)\right)\right)\right)\right)
\end{aligned}
$$




\subsubsection{Comparison of policy scenarios}

Comparing (14) to (5) shows that, in line with the idea of the hold up, the subsidy (and thus also investment) in period 2 is lower with discretion than with commitment, i.e. the optimal RES policy is time-inconsistent:

$$
s_{2}^{D N *}-s_{2}^{D C *}=-\frac{c_{2} n_{2}}{n_{1}}<0
$$

where $n_{2} \equiv l\left(b_{1}+b_{2} \delta+(1+l) v(1+\delta)\right)>0$.

Comparing (13) to (5) shows that this time inconsistency is partly compensated by a higher optimal subsidy in period 1 :

$$
s_{1}^{D N *}-s_{1}^{D C *}=\delta \frac{(1+l) c_{2} n_{2}}{(1+2 l) n_{1}}>0
$$

whose form can readily be interpreted as an offset of the period-2 subsidy shortfall discounted and corrected for the deadweight extra cost of an increase in the period-1 subsidy.

This higher period-1 subsidy notwithstanding, optimal investment in period 1 is still lower under full discretion, that is, the period-2 subsidy reduction dominates, as comparing (15) to (6) reveals:

$$
x_{1}^{D N *}-x_{1}^{D C *}=-\frac{\delta l c_{2} n_{2}}{c_{1}(1+2 l) n_{1}}<0
$$

Consequently, the comparison of (16) and (7) demonstrates that welfare is lower under discretion than under commitment:

$$
W^{D N *}-W^{D C *}=-\frac{\delta c_{2} n_{2}^{2}}{2 c_{1}(1+2 l) n_{1}}<0
$$

In a deterministic environment, where future benefits and costs of a RES subsidy are known, the social planner should therefore commit to a long-term RES policy path with single subsidy rates for each period.

\section{Optimal RES support with uncertain external benefits ( $(U)$}

We now consider uncertain external benefits of RES deployment. We first examine policy choices in a naïve setting, assuming that (a) uncertainty dissolves completely at the beginning of period 2, (b) political decision- makers are maximizing social welfare (even though this calculus is timeinconsistent), and (c) the representative private firm is risk-neutral. Subsequently, we will relax our naïve assumptions and discuss how our results change (a) if uncertainty dissolves only slowly, (b) if political decisions deviate arbitrarily from the intra-temporarily optimal choice, or (c) if the firm is riskaverse. For either setting, our analytical discussion will be complemented by a numerical illustration. 


\subsection{Naïve setting}

\subsubsection{Analytical approach}

In the following, we study unconditional commitment, rule-based commitment and discretion analytically.

\subsubsection{Unconditional commitment (UC)}

Since in each period, only a single subsidy is set, the firm's reaction functions are identical to those in the deterministic case, given in (2) and (3). If the social planner commits to a single subsidy rate for period 2, welfare is:

$$
\begin{aligned}
W^{U C}=V_{1}\left(q_{1}\right) & -C_{1}\left(x_{1}\right)-L_{1}\left(s_{1}, q_{1}\right)+B_{1}\left(q_{1}\right) \\
& +E_{i}\left[\delta\left(V_{2}\left(q_{2}\right)-C_{2}\left(x_{2}\right)-L_{2}\left(s_{2}, q_{2}\right)+B_{2 i}\left(q_{2}\right)\right)\right. \\
& \left.+\delta^{2}\left(V_{3}\left(q_{3}\right)-L_{3}\left(s_{2}, q_{3}\right)+B_{3 i}\left(q_{3}\right)\right)\right]
\end{aligned}
$$

Substituting the firm's reaction functions (2) and (3) into (21), deriving the first-order conditions for the welfare-maximizing subsidies $s_{1}$ and $s_{2}$ and solving the resulting equation system, yields the optimal subsidies, which are the same as those in (5), replacing the future benefit $b_{2}$ by its expectation value $E\left[b_{2}\right]$ for the period-2 subsidy. Substituting these subsidies back into (2) and (3) yields the optimal investment levels for both periods. These also correspond to $x_{t}^{D C *}$ from (6), with $b_{2}$ replaced by its expectation value $E\left[b_{2}\right]$.

Substituting these optimal investment levels into (21) yields welfare in the optimum:

$$
\begin{gathered}
W^{U C *}=\frac{1}{2 c_{1} c_{2}(1+2 l)}\left(b_{1}^{2} c_{2}+c_{1}\left(E\left[b_{2}\right]+(1+l) v\right)^{2} \delta(1+\delta)^{2}\right. \\
+c_{2}\left(E\left[b_{2}\right] \delta+(1+l) v(1+\delta)\right)\left(2 b_{1}\right. \\
\left.\left.+\left(E\left[b_{2}\right] \delta+(1+l) v(1+\delta)\right)\right)\right)
\end{gathered}
$$

The resulting welfare level also corresponds to that under commitment in the deterministic environment. Only the benefit parameter for period $2, b_{2}$, is replaced by its expectation value, $E\left[b_{2}\right]$. Thus, as long as $b_{2}=E\left[b_{2}\right]$, welfare is not affected by uncertainty under unconditional commitment, $W^{U C *}=W^{D C *}$.

\subsubsection{Rule-based commitment (UR)}

We now assume the social planner commits, in period 1, to implementing a state-contingent subsidy for periods 2 and 3, which depends on the eventual benefit parameter observed at the beginning of period 2. Consequently, the profit function of the representative firm is adapted as follows:

$$
\begin{aligned}
\pi^{U R}=p_{1} q_{1}- & C_{1}\left(x_{1}\right)+s_{1} q_{1} \\
& +E_{i}\left[\delta\left(p_{2} q_{2 i}-C_{2}\left(x_{2 i}\right)+s_{2 i} q_{2 i}\right)+\delta^{2}\left(p_{3} q_{3 i}+s_{2 i} q_{3 i}\right)\right]
\end{aligned}
$$


Thus, the firm now considers the subsidies and the corresponding investment and generation levels separately for the high- and low-subsidy state, weighted by the corresponding probabilities. Maximizing (23) with respect to investment levels in period 1 and 2 yields the first-order conditions from (2) and (3) but using the expectation value for $s_{2}$ :

$$
\begin{gathered}
x_{1}^{U R}=\frac{s_{1}+v+\delta\left(E\left[s_{2}\right]+v\right)}{c_{1}} \\
x_{2 i}^{U R}=\frac{\left(s_{2 i}+v\right)(1+\delta)}{c_{2}},
\end{gathered}
$$

where $E\left[s_{2}\right]=s_{2 H} \alpha+s_{2 L}(1-\alpha)$. Since there are now different investment and generation levels in the high- and low-benefit states, social welfare for rule-based commitment needs to be rewritten as:

$$
\begin{aligned}
W^{U R}=V_{1}\left(q_{1}\right) & -C_{1}\left(x_{1}\right)-L_{1}\left(s_{1}, q_{1}\right)+B_{1}\left(q_{1}\right) \\
& +E_{i}\left[\delta\left(\left(V_{2}\left(q_{2 i}\right)-C_{2}\left(x_{2 i}\right)-L_{2}\left(s_{2 i}, q_{2 i}\right)+B_{2 i}\left(q_{2 i}\right)\right)\right)\right. \\
& \left.+\delta^{2}\left(\left(V_{3}\left(q_{3 i}\right)-L_{3}\left(s_{2 i}, q_{3 i}\right)+B_{3 i}\left(q_{3 i}\right)\right)\right)\right]
\end{aligned}
$$

Substituting (24) into (25), deriving the first-order conditions for the welfare-maximizing subsidies $s_{1}$ and $s_{2 i}$, and solving the resulting equation systems yields the optimal, state-contingent subsidy schedule:

$$
\begin{gathered}
s_{1}^{U R *}=\frac{b_{1}-l v}{1+2 l} \\
s_{2 i}^{U R *}=\frac{b_{2 i}-l v}{1+2 l}
\end{gathered}
$$

That is, the social planner simply commits to adopting the Pigouvian subsidy, of the form familiar from above, that would be optimal in each period and state.

Inserting (26) into (24) gives the state-contingent optimal investment levels, again similar to $x_{t}^{D C *}$ from (6), but with expectation and state-contingent values of $b_{2}$ in period 1 and 2 , respectively,

$$
\begin{gathered}
x_{1}^{U R *}=\frac{b_{1}+\delta E\left[b_{2}\right]+(1+\delta)(1+l) v}{c_{1}(1+2 l)} \\
x_{2 i}^{U R *}=\frac{(1+\delta)\left(b_{2 i}+(1+l) v\right)}{c_{2}(1+2 l)}
\end{gathered}
$$

Substituting (26) and (27) into (25), we can derive welfare in the optimum:

$$
W^{U R *}=W^{D C *}+\frac{\sigma_{b}^{2} \delta(1+\delta)^{2}}{2 c_{1} c_{2}(1+2 l)}
$$

While uncertainty would generally be seen as costly, we find an unambiguous increase of welfare compared to the deterministic case, in which $c_{2}=E\left[c_{2}\right]$. The reason is that option value means society 
benefits from variability of damage around the expectation value, by adjusting the future policy to the future costs. Clearly, however, welfare under uncertainty is lower compared to the weighted average of welfare of two deterministic worlds with $c_{2}=c_{2 H}$ and $c_{2}=c_{2 L}$, respectively.

\subsubsection{Discretion (UN)}

The problem of optimal policies under discretion is solved by backward induction, as in the deterministic environment. The firm's first-order conditions for profit-maximizing investment in period 2 correspond to those derived for rule-based commitment given in (24). The social planner in period 2 aims to identify the subsidy that maximizes welfare for a given period-1 investment. When taking this decision, the social planner knows whether the high- or the low-benefit state has materialized for period 2 . Consequently, a state-contingent welfare function applies:

$$
W_{2 i}^{U N}=\sum_{t=2}^{3}\left\{\delta^{t-2}\left[V_{2}\left(q_{t i}\right)-L_{t}\left(s_{t i}, q_{t i}\right)+B_{t i}\left(q_{t i}\right)\right]\right\}-C_{2}\left(x_{2 i}\right)
$$

The subsequent solution approach is equivalent to that under discretion in the deterministic setting. Substituting (24) into (29), we can derive the welfare-maximizing subsidies in either state as a function of period-1 investment, $s_{2 i}^{U N}\left(x_{1}\right)$. Inserting these subsidy functions back into (24) gives the optimal investment levels in period 2 as a function of period-1 investment, $x_{2 i}^{U N}\left(x_{1}\right)$. Using these functional relationships, the firm's first-order condition for optimal investment in period 1, given in (24), can be adjusted, and we can derive the optimal period-2 subsidy as well as the (state-contingent) investment levels in periods 1 and 2 as functions of the period-1 subsidy, $s_{2 i}^{U N}\left(s_{1}\right), x_{1}^{U N}\left(s_{1}\right)$ and $x_{2 i}^{U N}\left(s_{1}\right)$. We abstain from presenting the corresponding, lengthy equations. ${ }^{5}$ Substituting them into the welfare function given in (25) and maximizing welfare with respect to the period-1 subsidy yields the optimal subsidy for period 1 , and subsequently also the other optimal state-contingent subsidy for period 2 . We assume in the following that the expected period-2 benefit corresponds to the one assumed in the deterministic setting, $E\left[b_{2}\right]=b_{2}$ :

$$
\begin{gathered}
s_{1}^{U N *}=s_{1}^{D N *} \\
s_{2 i}^{U N *}=s_{2}^{D N *}+\frac{b_{2 i}-E\left[b_{2}\right]}{1+2 l}
\end{gathered}
$$

We see that with uncertainty, the period-2 subsidy is corrected by the deviation of the state's benefit from the expected benefit. The corresponding optimal investment levels are:

$$
x_{1}^{U N *}=x_{1}^{D N *}
$$

\footnotetext{
${ }^{5}$ The interim derivation steps can be obtained from the authors upon request.
} 


$$
x_{2 i}^{U N *}=x_{2}^{D N *}+\frac{\left(b_{2 i}-E\left[b_{2}\right]\right)(1+\delta)}{c_{2}(1+2 l)}
$$

Substituting (30) and (31) into (25) yields welfare in the optimum:

$$
W^{U N *}=W^{D N *}+\frac{\sigma_{b}^{2} \delta(1+\delta)^{2}}{2 c_{2}(1+2 l)}
$$

\subsubsection{Comparison of policy scenarios}

When comparing the outcomes of the policy scenarios under uncertain benefits, we will focus on the welfare differences. Comparing (28) to (22) and (32) shows that rule-based commitment strictly dominates both, unconditional commitment and discretion:

$$
\begin{gathered}
W^{U R *}-W^{U C *}=\frac{\sigma_{b}^{2}(1+\delta)^{2}}{2 c_{2}(1+2 l)}>0 \\
W^{U R *}-W^{U N *}=\frac{\delta c_{2} n_{2}^{\prime 2}}{2 c_{1}(1+2 l) n_{1}}>0
\end{gathered}
$$

with $n_{2}^{\prime} \equiv l\left(b_{1}+E\left[b_{2}\right] \delta+(1+l) v(1+\delta)\right)$, which corresponds to $n_{2}$ with $b_{2}$ replaced by $E\left[b_{2}\right]$.

However, perfect rule-based commitment presents a more theoretical benchmark, as it is very demanding in terms of information and contracting (see, e.g., Lohmann, 1992). First, in period 1, the social planner needs to be aware of the possible period-2 states. In practice, it is challenging to identify these states and to contract the corresponding state-contingent subsidies. Second, in period 2, the social planner needs to be able to legally identify which state has materialized. This is difficult if the planner is not perfectly informed, if uncertainty has not vanished entirely, or if information is not unambiguous. In the face of these practical constraints, rule-based commitment can easily degenerate into a setting in which the social planner opts to commit to a simplified set of states and subsidies. Unconditional commitment is one extreme case for this setting. On the other end of the possible spectrum, rule-based commitment may also degenerate into unconstrained discretion. This happens if the social planner deliberately opts for non-commitment in period 1 because he is aware of his ignorance of possible period-2 states - or if she has certain degrees of freedom in period 2 because the actual state cannot be perfectly identified. For practical policy-making, the key question therefore is how desirable it seems to commit without optimal rules, or to instead not commit at all.

Comparing (22) and (32) shows that the difference between unconditional commitment and full discretion is ambiguous in sign: 


$$
\begin{aligned}
W^{U C *}-W^{U N *} & =\frac{1}{2 c_{1} c_{2}(1+2 l)}\left(\frac{\delta c_{2}^{2} n_{2}^{\prime 2}}{n_{1}}-c_{1} \sigma_{b}^{2}(1+\delta)^{2}\right) \\
& =\frac{1}{2 c_{1} c_{2}(1+2 l)}\left(\frac{\delta c_{2}^{2} l^{2}\left(b_{1}+E\left[b_{2}\right] \delta+(1+l) v(1+\delta)\right)^{2}}{(1+4 l)(1+\delta)^{2}+l^{2}\left(4+9 \delta+4 \delta^{2}\right)}\right. \\
& \left.-c_{1} \sigma_{b}^{2}(1+\delta)^{2}\right)
\end{aligned}
$$

Equation (34) illustrates that the difference between unconditional commitment and full discretion is always increasing (i.e. unconditional commitment becomes more favorable) with increasing consumer benefits from RES generation, $v$, and increasing (expected) benefits of RES deployment in period 1 and $2, b_{1}$ and $E\left[b_{2}\right]$. Higher values for these parameters increase the societal benefits foregone by underinvestment in the case of discretion.

The difference between unconditional commitment and discretion is decreasing (i.e. discretion becomes more favorable) with

- an increasing variance of the benefits $\sigma_{b}^{2}$. Higher variance means a larger welfare gain from having the discretion to adjust the RES subsidy in period 2 to the correct benefit level (discretion is most desirable in cases where $\alpha=0.5$, as this value maximizes variance in benefits for any given state benefit difference $b_{2 H}-b_{2 L}$ ), and

- an increasing period-1 and/or a decreasing period-2 cost parameter, $c_{1}$ and $c_{2}$ respectively, i.e. increasing exogenous technological progress, as in both cases, investments are shifted from period 1 to period 2, and underinvestment due to hold-up of period-1 investments under discretion thus becomes less important.

It remains analytically ambiguous how the difference between unconditional commitment and discretion is affected by

- the welfare costs from the RES subsidy, $l$. On the one hand, this parameter increases the incentive for the social planner to deviate from the ex-ante optimal subsidy path and, thus, fosters underinvestment in period 1 under discretion (i.e. commitment becomes more favorable). On the other hand, if the deadweight loss becomes too large, the subsidies become so small that no RES build is incentivized under either policy, and therefore the loss from discretion vanishes.

- the discount factor $\delta$. On the one hand, a higher discount factor implies that the welfare loss from underinvestment in period 1 becomes more important and welfare gains from possible subsidy adjustments in period 2 become less relevant (i.e. commitment becomes more favorable). On the other hand, a higher discount factor also implies that future adjustments to the RES subsidy become less important for the firm's decision on period-1 investments (i.e. discretion becomes less harmful). 


\subsubsection{Numerical illustration}

For a simple numerical application we use the values provided in Table 2. We assume that each period consists of a decade. In this case the discount factor $\delta=0.63$ corresponds to a modest annual discount rate of $4.5 \%$. The values roughly represent the case of a modern onshore wind farm, for which we assume levelized capital costs of roughly $70 € / \mathrm{MWh}$ for the $200^{\text {th }} \mathrm{GW}$ of installed capacity, raising linearly to $140 € / \mathrm{MWh}$ for the $400^{\text {th }} \mathrm{GW}$ in period 1 . Technological progress reduces this cost function proportionally by some $36 \%$ in period 2 , so that the $200^{\text {th }} \mathrm{GW}$ has levelized costs of $45 € / \mathrm{MWh}$. The load-factor is assumed to be $20 \%$ throughout a 20 year lifetime of the plants. We assume a captured electricity (wholesale) price of $30 € / \mathrm{MWh}$ which is somewhat below average wholesale prices, reflecting wind 'cannibalization', i.e., that the correlation of wind output across farms means wind farms tend to yield a lower-than-average market price for their power. We assume an emission intensity of 0.75 $\mathrm{tCO}_{2} / \mathrm{MWh}$ for the conventional electricity which, we assume, is replaced by electricity generation from wind power. The value of $b_{1}=0.92 \mathrm{bn} € / \mathrm{GW}$ corresponds to an average value of $70 € / \mathrm{tCO}_{2}$ for emissions avoidance through wind energy. Benefits in period $2, b_{2 L}$ and $b_{2 H}$, correspond to a $50 \%$ chance for a low climate externality of $50 € / \mathrm{tCO} 2$ and a $50 \%$ chance of a higher externality of $90 € / \mathrm{tCO} 2$, with the same expected value as in period 1 . The loss parameter, $l$, is $30 \%$, in line with a typical deadweight loss factor of public finances. Based on these assumptions we get the numerical results provided in Table 3. 
Table 2: Parameter values assumed for the main scenario

\begin{tabular}{cccl}
\hline & Value & Unit & Corresponding value in standard unit \\
\hline$\delta$ & 0.631 & & $4.5 \%$ p.a. \\
$v$ & 0.53 & $\mathrm{bn} € / \mathrm{GW}$ & $30 € / \mathrm{MWh}$ \\
$c_{1}$ & 0.0082 & $\mathrm{bn} € / \mathrm{GW}^{2}$ & $70 € / \mathrm{MWh}$ levelized capex at $200 \mathrm{GW}$ \\
$c_{2}$ & 0.0053 & $\mathrm{bn} € / \mathrm{GW}^{2}$ & $45 € / \mathrm{MWh}$ levelized capex at $200 \mathrm{GW}$ \\
$l$ & 0.3 & & \\
$b_{1}, b_{2}, E\left[b_{2}\right]$ & 0.92 & $\mathrm{bn} € / \mathrm{GW}$ & $70 € / \mathrm{tCO}_{2}$ \\
$b_{2}^{L}$ & 0.66 & $\mathrm{bn} € / \mathrm{GW}$ & $50 € / \mathrm{tCO}_{2}$ \\
$b_{2}^{H}$ & 1.18 & $\mathrm{bn} € / \mathrm{GW}$ & $90 € / \mathrm{tCO}_{2}$ \\
$\alpha$ & 0.5 & & \\
\hline
\end{tabular}

Table 3: Results for the main scenario

\begin{tabular}{|c|c|c|c|c|c|c|c|}
\hline & & & $\begin{array}{l}\text { Dete } \\
\text { env }\end{array}$ & & Unce & extern & efits \\
\hline & & Unit & $\mathrm{DC}$ & DN & $\mathrm{UC}$ & UR & UN \\
\hline & & & 0.48 & 0.51 & 0.48 & 0.48 & 0.51 \\
\hline & $s_{2}^{H}$ & bn€/GW & & & & 0.64 & 0.57 \\
\hline $5_{2}$ & $s_{2}^{L}$ & & & & & 0.31 & 0.24 \\
\hline & & & 27.2 & 29.3 & 27.2 & 27.2 & 29.3 \\
\hline & $s_{2}^{H}$ & $€ / M W h$ & & & & 37 & 32 \\
\hline$J_{2}$ & $s_{2}^{L}$ & & & & & 17.8 & 13.6 \\
\hline & & & 199 & 198 & 199 & 199 & 198 \\
\hline & $x_{2}^{H}$ & GW/decade & & & & 361 & 338 \\
\hline & $x_{2}^{L}$ & & & & & 259 & 236 \\
\hline & & bn€ & 516.2 & 514.8 & 516.2 & 523.1 & 521.7 \\
\hline
\end{tabular}

We note two key insights from Table 3: First, in our naïve setting with uncertain benefits, discretion outperforms unconditional commitment. This points to the fact that with the parameter values we assume, benefits from flexibility are more important than deadweight losses: The benefit from getting the benefit right more than outweighs the cost of opportunistic regulatory behavior aiming at limiting the financing burden. Second, the differences in welfare between the policy scenarios are generally very small. In the deterministic scenario, discretion only reduces welfare by $0.3 \%$. With uncertain benefits, 
discretion is only by $1 \%$ superior to unconditional commitment in terms of welfare. Moreover, both unconditional commitment and discretion come very close to the first-best policy scenario of rule-based commitment, with welfare losses of only $1.3 \%$ and $0.3 \%$, respectively. This implies that both timeinconsistent policy making and benefit uncertainty are overall minor issues for policy choice in our naïve setting.

Given that the comparison between the policy scenarios is extremely tight in our main scenario, we carry out sensitivity analyses to examine the validity of our findings more thoroughly. We will primarily shed light on the comparison between unconditional commitment and discretion because this comparison is analytically ambiguous, and because we believe these policy scenarios are the most relevant ones in practice, as pointed out above.

Figure 2, Figure 3 and Figure 4 illustrate that the superiority of discretion in our naïve setting is robust for reasonable ranges of the (expected) benefit from RES deployment $\left(b_{1}, E\left[b_{2}\right]\right)$, the discount factor $(\delta)$ and exogenous technological progress (i.e., the share by which the cost parameter $c_{2}$ is below $c_{1}$ ). The impact of the deadweight loss $l$ on the welfare wedge between unconditional commitment and discretion merits a closer look. The bigger the deadweight loss, the larger is the social planner's incentive to deviate from the ex-ante optimal policy path under discretion - and the more preferable becomes commitment. Figure 5 illustrates, however, that for reasonable levels of the deadweight loss, i.e. for $l<$ 1, discretion outperforms commitment with our calibration. Yet, we also argue in Section 2.1 that $l$ may not only represent the deadweight loss of policy intervention in the narrower sense but additionally also other social or political overhead cost related to covering the expenditure for the subsidy, e.g. losses in political popularity due to higher electricity prices. In this case, one can easily imagine $l>1$, and commitment outperforming discretion in terms of welfare. In the following sections, we provide additional sensitivity analyses by relaxing some of the assumptions underlying our naïve setting.

Figure 2: Welfare impact of commitment $W_{U C}-W_{U N}$ : Sensitivity to (expected) benefit from RES deployment $b_{1}$ or $E\left[b_{2}\right]$

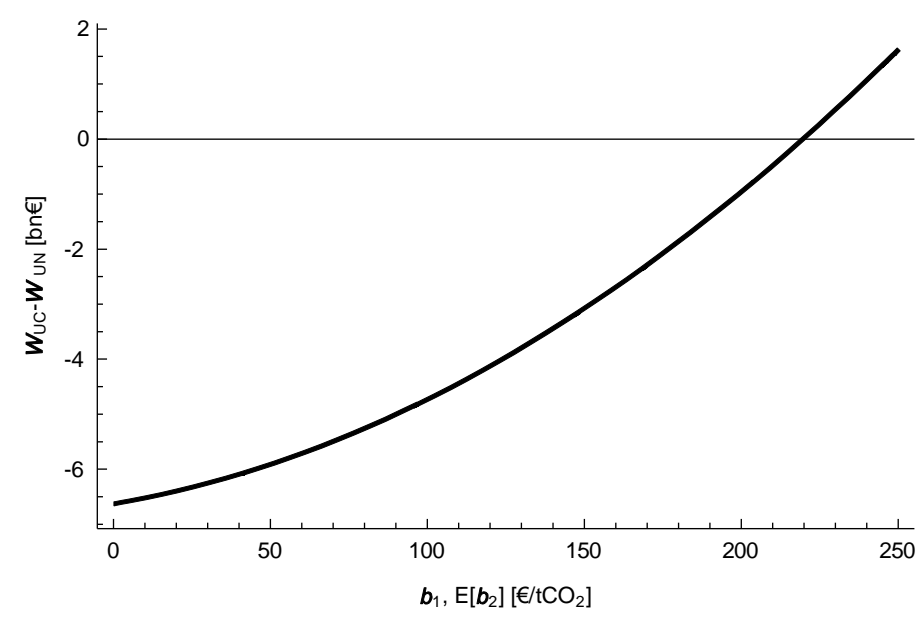


Figure 3: Welfare impact of commitment $W_{U C}-W_{U N}$ : Sensitivity to discount factor $\delta$

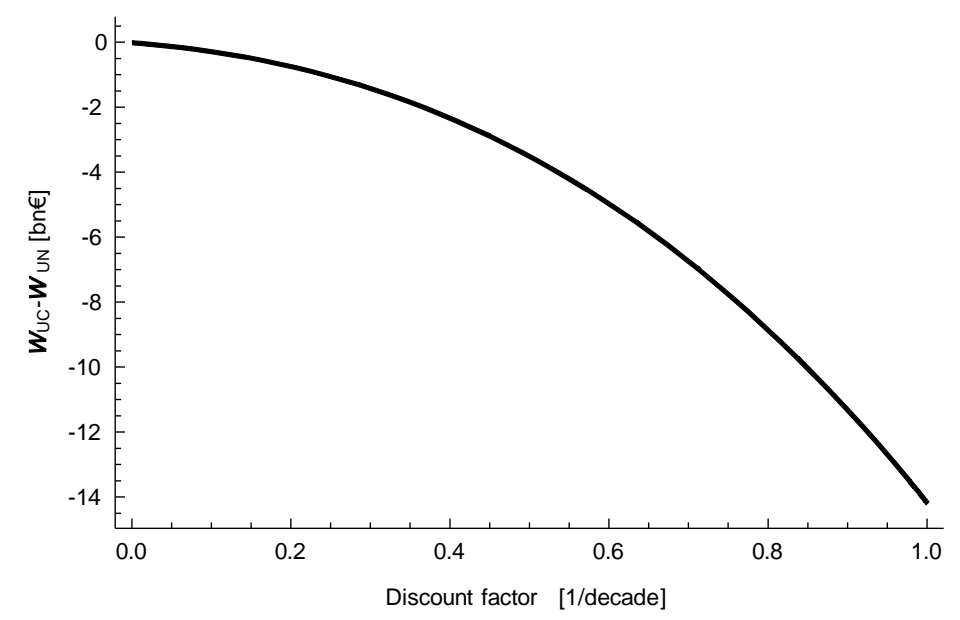

Figure 4: Welfare impact of commitment $W_{U C}-W_{U N}$ : Sensitivity to technological progress (relative change of cost parameter from $c_{1}$ to $c_{2}$ )

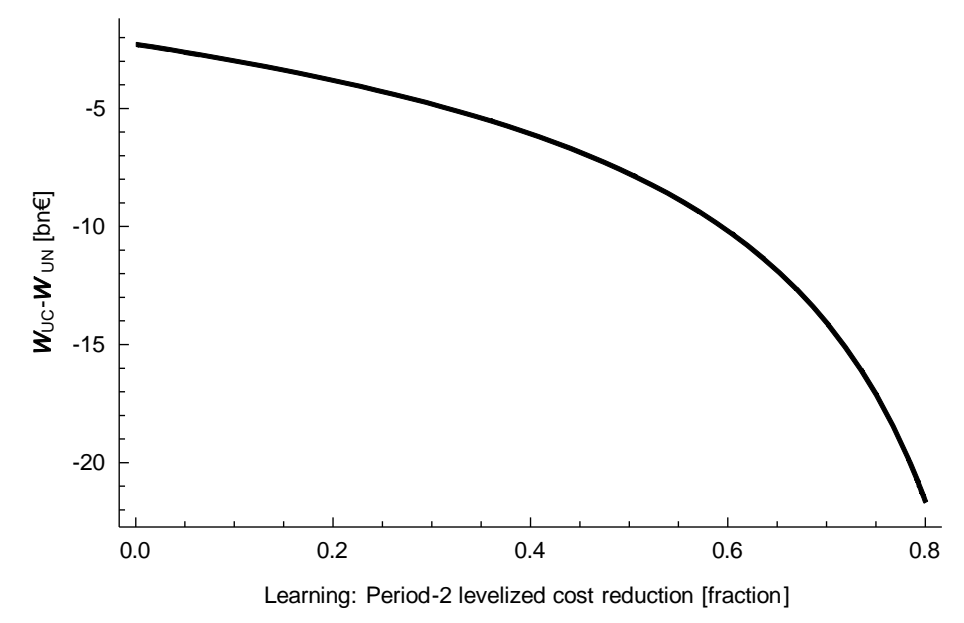

Figure 5: Welfare impact of commitment $W_{U C}-W_{U N}$ : Sensitivity to deadweight loss $l$

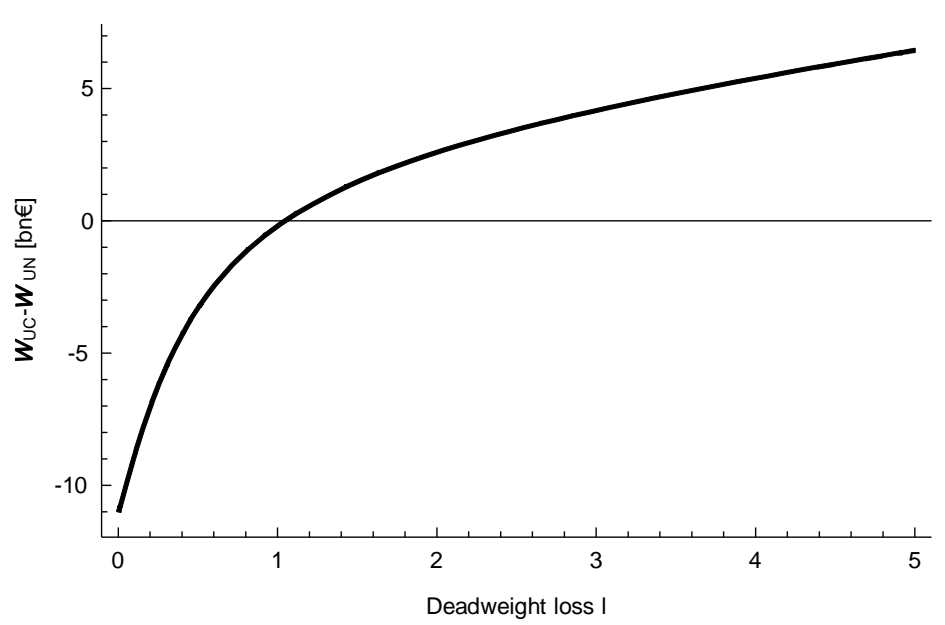




\subsection{Slow dissolution of uncertainty}

So far, we have assumed that the uncertainty regarding the external benefits of RES deployment vanishes completely at the beginning of period 2 . However, in practice, uncertainty is likely to decline only partly from one period to another. And for short periods, the reduction in uncertainty may in fact be very small (see, e.g., Kelly and Kolstad, 1999; Kelly and Tan, 2015; Roe and Baker, 2007). In our modeling framework, the case of uncertainty vanishing only slowly and partly over time corresponds conceptually to the case where a small initial uncertainty vanishes completely at the beginning of period 2 . Thus, the impact of incomplete reduction of uncertainty can be understood by examining how sensitively the welfare difference between unconditional commitment and discretion responds to changes in the degree of uncertainty. This sensitivity is illustrated in Figure 6, which extends Figure 5 by a third dimension for the standard deviation of the benefit, $\sigma_{b}$, here proxying the share of the benefit uncertainty that gets resolved by the start of period 2 .

\section{Figure 6: Welfare impact of commitment $W_{U C}-W_{U N}$ : Sensitivity to deadweight loss $l$ and} standard deviation of the external benefit $\sigma_{b}$ (yellow plain shows the zero level)

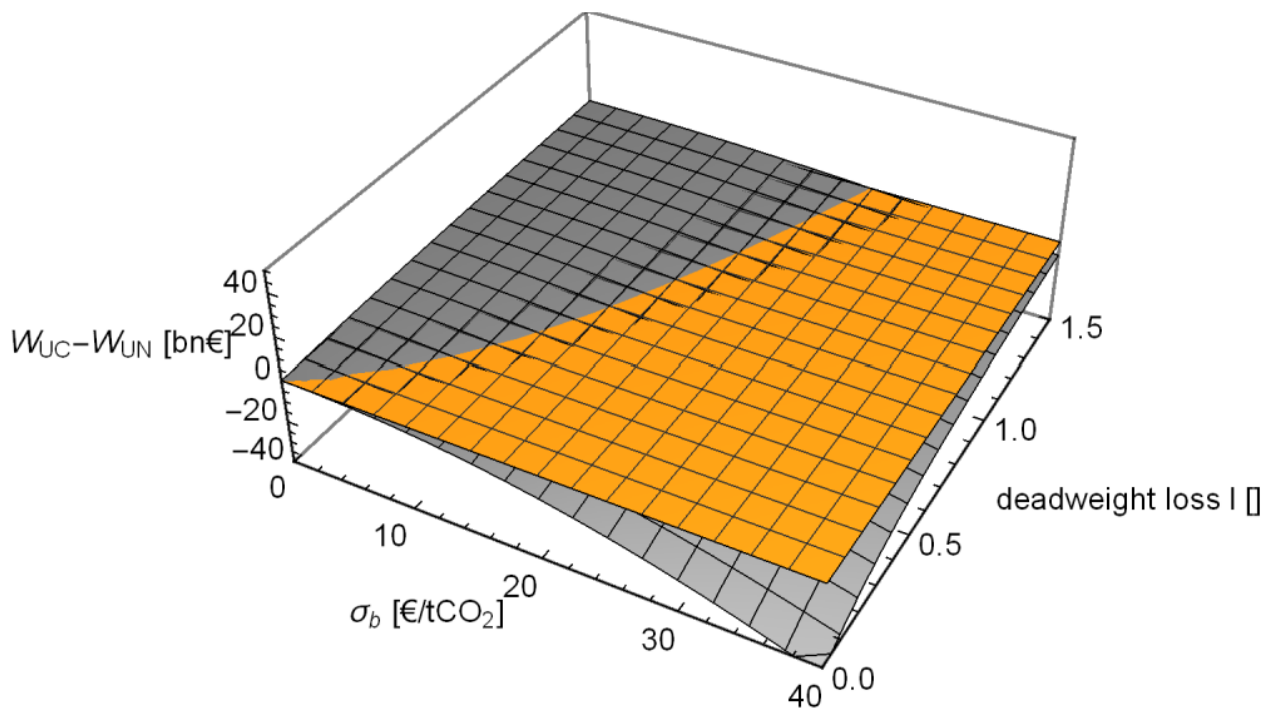

Assuming that period 1 consists of ten years in our calibration, it seems reasonable to assume that the actual reduction in uncertainty materializing at the beginning of period 2 may be very small indeed. Figure 6 underpins numerically how commitment becomes more favorable in terms of welfare with decreasing levels of uncertainty (or of uncertainty dissolution). If uncertainty is small, unconditional commitment outperforms discretion for reasonable values of the deadweight loss (e.g. $l>0.3$ ). Yet, Figure 6 also shows that the welfare gain from commitment is rather small for a given small degree of uncertainty (dissolution), even for higher levels of the deadweight loss. Thus, in general, there would seem not much to win from commitment either. 


\subsection{Political arbitrariness}

So far we have assumed that policy-making may be time-inconsistent if we allow for discretion but still follows an intra-temporal social optimization approach which in period 2 balances (then more certain) benefits from RES deployment and costs (investment costs, deadweight loss). However, it may not be particularly realistic to assume policy updates of future governments to be solely based on new, climaterelevant information. Instead, future governments may in addition exhibit some idiosyncratic degree of climate concern and willingness to act upon it. The future government's taste is thus not necessarily aligned with today's taste, and a current society or government, with its given taste for climate mitigation, may thus find future policy choices as somewhat arbitrary in the sense of departing from what current tastes would imply. We here explore what implications such 'arbitrariness' of future governments implies for the trade-off between unconditional commitment and discretion.

To capture the (perceived) arbitrariness of future planners' choices in the eye of the current policy maker, we assume that, absent any commitment, the future government arbitrarily deviates from the theoretically subgame-perfect levels when setting the period-2 subsidy. There is only noise but no directed bias, that is, we assume deviations to be a symmetric noise: If, for an uncommitted government, $s_{2 i}^{U A N *}$ was the optimal subgame-perfect period-2 subsidy for a given benefit state $i$, then it would choose $s_{2 i, a}^{U A N}=s_{2 i}^{U A N *}[ \pm]_{a} A$, where $a \in\{H, L\}$, the two possible states or 'moods' of the future government, $H$ and $L$ for the high- and low-subsidy moods, $[ \pm]_{a}$ a state-contingent sign, $[ \pm]_{a} \equiv\{+$ if $a=$ $H$; - if $a=L\}$, and therefore $A$ the magnitude of the directed subsidy deviations (superscript $A$ denotes the case with arbitrariness). We rule out arbitrary period-2 deviations if the future subsidy rates are committed to from the first period, that is, we assume arbitrary deviations happen only in the noncommitment case. We therefore have $W^{U A C *}=W^{U C *}$. Period-2 deviations are known unknowns in period-1, that is, non-committing period-1 planning takes into account that the period-2 policies will exhibit some arbitrariness. The mood is revealed before period-2 investment is defined. The solution approach corresponds to that outlined for discretion above. The major difference consists in the fact that the social planner and the private investor now consider four possible states for period $2[\cdot]_{2 i, a}$ when making their policy and investment choices.

We find that within this framework, the expectation values for subsidy and investment, aggregated over the government's possible moods, equal those of the case without arbitrariness:

$$
s_{1}^{U A N}=s_{1}^{U N} \quad x_{1}^{U A N}=x_{1}^{U N} \quad E_{a}\left[s_{2 i, a}^{U A N}\right]=s_{2 i}^{U N} \quad E_{a}\left[x_{2 i, a}^{U A N}\right]=x_{2 i}^{U N}
$$

The arbitrariness does, however, impact welfare, which becomes

$$
W^{U A N *}=W^{U N *}-\frac{2 A^{2}(1+l) \delta(1+\delta)^{2}}{c_{2}}
$$


Thus, arbitrariness strictly reduces the welfare under discretion, and makes discretion relatively less attractive compared to commitment. This reduction is proportional to the variance of the policy arbitrariness, $A^{2}$. In our numerical example, the loss from a period-2 policy subsidy arbitrariness $A$ of just around $10 € / M W h$ (this may be a plausible value; in our main scenario the optimal subsidy rate for period 2 varies from 13 to $37 € / \mathrm{MWh}$ ) is enough to make unconditional commitment superior to discretion for all plausible ranges of benefit uncertainty, as illustrated in Figure 7.

Figure 7: Welfare impact of commitment with arbitrariness $\left(W_{U A C}-W_{U A N}\right)$ : Sensitivity to standard deviation of the benefit $\sigma_{b}$ and of the political arbitrariness $\sigma_{A}$ (yellow plain shows the zero level)

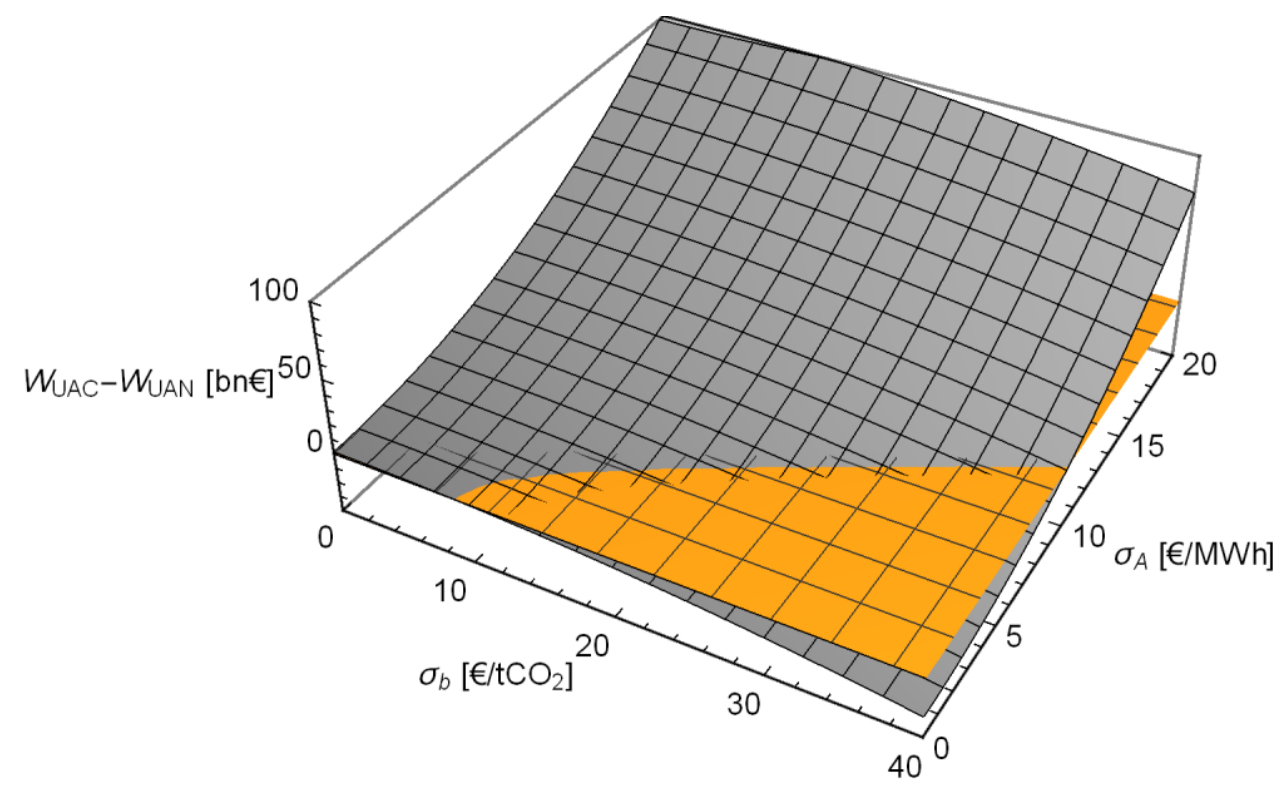

\subsection{Risk aversion}

We have so far not explicitly accounted for the impact of uncertainty on choices and welfare, and instead resorted to expectation values of financial turnouts as a basis for the evaluation of incentives and welfare. This contrasts to decreasing returns in utilities with respect to financial turnout, aka risk-aversion. Together with uncertainty, this often leads to project evaluations using high discount rates for returns to investments, especially by private actors who are seen to typically have much larger hurdle rates than governments. While the latter tend to require return rates close to the near-zero return rates often characteristic for government bond yields, private firms do not rarely require double-digit returns in central financial forecasts for their projects with uncertain payoffs to go ahead. If the government tries to incentivize private investments, these incentives may thus be downscaled according to the degree of uncertainty around them.

As a somewhat stylized way to capture this high degree of private discounting of uncertain payoffs, we assume the private investors to exhibit a certain skepticism against uncertain future subsidies. We thus consider the case where firms' investment decisions are based on reduced period-2 and 3 revenue 
expectations in the case of a discretionary policymaker. While this is a somewhat stylized proxy for a subtle concept of risk-aversion, it captures the first-order effect of firms penalizing uncertain payoffs, and it allows keeping the problem analytically tractable while it rapidly would become intractable with any more explicit modeling of risk-averse behavior, e.g. deviating private and social discount rates.

Writing $Z$ for the risk premium imposed on period- 2 and -3 revenues in the case of discretion, one can readily verify that the firms behave according to the changed investment first-order conditions

$$
\begin{gathered}
x_{1}^{U Z N}=\frac{s_{1}+v+\delta\left(E\left[s_{2}\right]-Z+v\right)}{c_{1}} \\
x_{2 i}^{U Z N}=\frac{\left(s_{2 i}+v\right)(1+\delta)-\delta Z}{c_{2}},
\end{gathered}
$$

Using this behavioral rule for firms, for substitution in the planner's welfare function from the basic case of discretion, $W^{U N}$, and solving the game analogously to that case, we naturally find the same welfare as in the basic case of discretion when $Z=0,\left.W^{U Z N *}\right|_{Z=0}=W^{U N *}$, and a reduction of the welfare as the discounting penalty, $Z$, increases up to any plausible value, $\left.\frac{\partial W^{U Z N *}}{\partial Z}\right|_{0 \leq Z \leq E\left[b_{2}\right] / l}<0$. We omit the lengthy terms for the welfare difference $W^{U Z N *}-W^{U N *}$, as well as it's derivative with respect to the risk premium $Z .{ }^{6}$ Figure 8 illustrates how the increasing risk premium $Z$ further decreases the case for discretion. For plausible values of the resolved benefit uncertainty, commitment appears clearly superior to discretion, even for a low risk-premium $Z$.

Figure 8: Welfare impact of commitment with risk aversion $\left(W_{U Z C}-W_{U Z N}\right)$ : Sensitivity to standard deviation of the benefit $\sigma_{b}$ and risk premium $Z$ (yellow plain shows the zero level)

\footnotetext{
${ }^{6}$ Detailed results are available from the authors. For positive losses $l<1, Z \leq E\left[b_{2}\right] / l$ represents only a formal restriction; a policy-uncertainty induced reduction of the accounted firm revenues by more than the expected benefit and hence by more than the expected subsidy rate itself, would be incompatible with our explanation based on discounting of uncertain subsidies.
} 


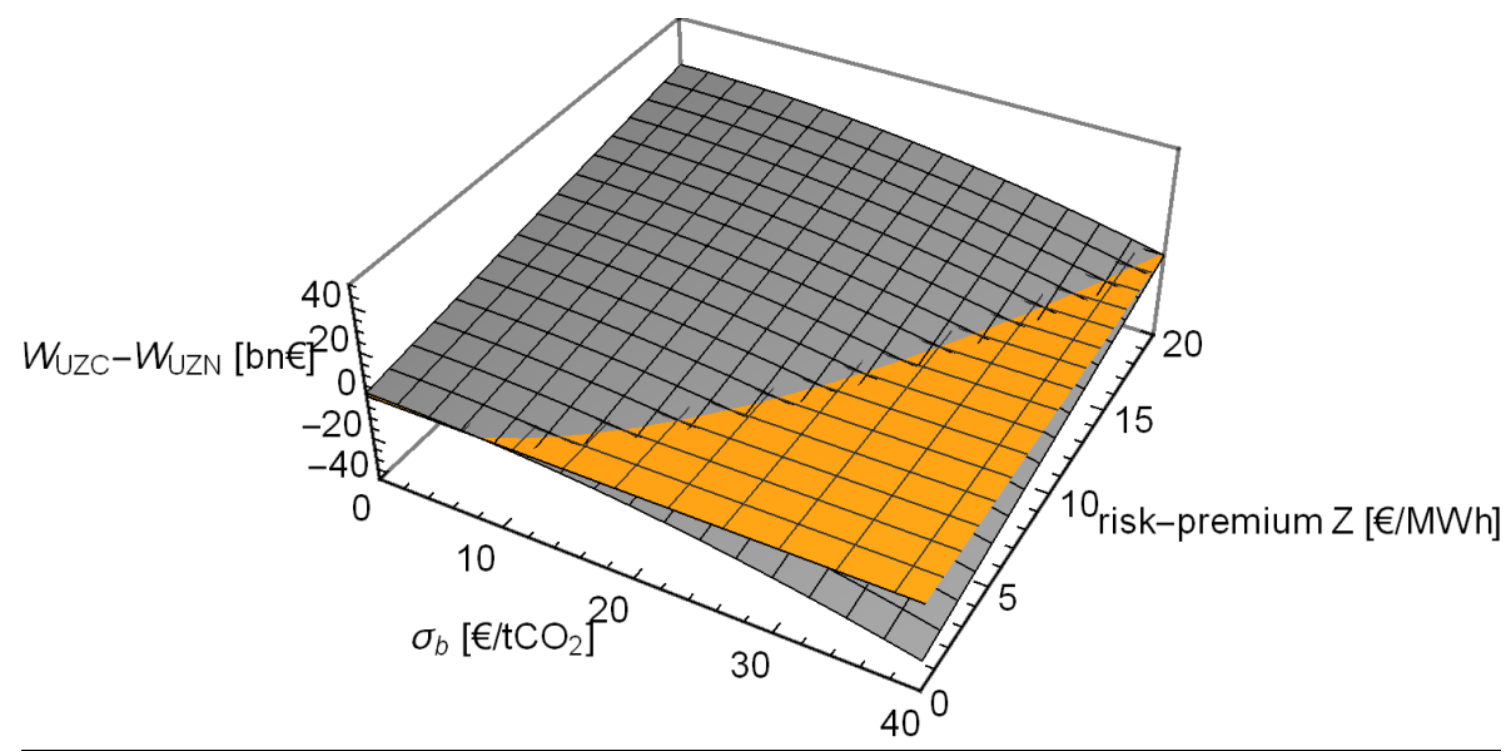

\section{Optimal RES support with uncertain investment costs (UK)}

There is, however, not only substantial uncertainty about the external benefits of RES deployment. The evolution of renewables investment costs is also highly uncertain. We will first analyze how uncertain costs affect policy choices in the Pigouvian setting we have assumed so far, i.e., if the RES subsidy is meant to internalize a (now certain) external benefit. In addition, we will also examine optimal RES support with uncertain costs in a standard-price-setting, i.e. if the subsidy is implemented to attain an exogenously given RES deployment target. While uncertainty in benefits (assumed in the previous section) does not affect the RES subsidy if this is to attain an exogenously given political RES target, we will see here the implications of a target on the choice between RES policy commitment and discretion if costs are uncertain. Again, we will look at the three sets of policy scenarios introduced above: unconditional commitment, rule-based commitment and discretion. Our simple setup will illustrate how closely related rule-based commitment is to unconditional commitment in a Pigouvian setting, and to discretion in a standard-price setting.

\subsection{Analytical approach: Pigouvian case}

If costs are uncertain, the general profit function the representative firm aims to maximize takes into account the two possible states for period 2 and is given as:

$$
\begin{aligned}
\pi^{U K}=p_{1} q_{1}- & C_{1}\left(x_{1}\right)+s_{1} q_{1} \\
& +E_{i}\left[\delta\left(p_{2} q_{2 i}-C_{2 i}\left(x_{2 i}\right)+s_{2 i} q_{2 i}\right)+\delta^{2}\left(p_{3} q_{3 H}+s_{2 H} q_{3 H}\right)\right]
\end{aligned}
$$

From (37) the (state-contingent) first-order conditions for optimal investment in period 1 and 2 can be derived:

$$
x_{1}^{U K}=\frac{s_{1}+v+\delta\left(E\left[s_{2}\right]+v\right)}{c_{1}}
$$




$$
x_{2 i}^{U K}=\frac{\left(s_{2 i}+v\right)(1+\delta)}{c_{2 i}}
$$

The social planner aims to maximize welfare which is given as:

$$
\begin{aligned}
W^{U K}=V_{1}\left(q_{1}\right) & -C_{1}\left(x_{1}\right)-L_{1}\left(s_{1}, q_{1}\right)+B_{1}\left(q_{1}\right) \\
& +E_{i}\left[\delta\left(V_{2}\left(q_{2 i}\right)-C_{2 i}\left(x_{2 i}\right)-L_{2}\left(s_{2 i}, q_{2 i}\right)+B_{2}\left(q_{2 i}\right)\right)\right. \\
& \left.+\delta^{2}\left(V_{3}\left(q_{3 H}\right)-L_{3}\left(s_{2 H}, q_{3 H}\right)+B_{3}\left(q_{3 H}\right)\right)\right]
\end{aligned}
$$

\subsubsection{Unconditional commitment (UKC)/Rule-based commitment (UKR)}

If the regulator commits to a single subsidy for period 1 and 2 , the firm's reaction functions given in (38) simplifies to:

$$
\begin{gathered}
x_{1}^{U K C}=\frac{s_{1}+v+\delta\left(s_{2}+v\right)}{c_{1}} \\
x_{2 i}^{U K C}=\frac{\left(s_{2}+v\right)(1+\delta)}{c_{2 i}}
\end{gathered}
$$

Substituting (40) into (39), assuming that $s_{2}=s_{2 H}=s_{2 L}$, deriving the first-order conditions for the welfare-maximizing subsidies, and solving the resulting equation system yields the optimal subsidy rates:

$$
s_{t}^{U K C *}=\frac{b_{t}-l v}{1+2 l}=s_{t}^{U K R *}
$$

Not surprisingly, these subsidy rates correspond to those in the deterministic setting. Since the Pigouvian subsidy level is set irrespectively of the cost parameter, it is not affected by cost uncertainty. This also implies that the rule-based commitment coincides with unconditional commitment, i.e. there is no statecontingency needed for period 2. These observations hinge on our assumption of linear benefits. Assuming convex or concave benefits instead would imply that the Pigouvian subsidy is also a function of electricity generation. In this case cost uncertainty would affect the optimal level of RES investment chosen, and thus have a second-order impact on the Pigouvian subsidy as well.

Substituting (41) back into (40), we derive the optimal investment levels:

$$
\begin{gathered}
x_{1}^{U K C *}=x_{1}^{U K R *}=\frac{b_{1}+\delta b_{2}+(1+\delta)(1+l) v}{c_{1}(1+2 l)} \\
x_{2 i}^{U K C *}=x_{2 i}^{U K R *}=\frac{(1+\delta)\left(b_{2}+v+l v\right)}{c_{2 i}(1+2 l)}
\end{gathered}
$$

These investment levels again largely correspond to those chosen in the deterministic environment. The firm's choice in period 2 is slightly adjusted as $c_{2}$ is replaced by the state-contingent $c_{2 i}$. 
Inserting (41) and (42) into (39) yields welfare in the optimum. We assume in the following that the expected period- 2 cost parameter corresponds to the one assumed in the deterministic setting, $E\left[c_{2}\right]=$ $c_{2}$ :

$$
W^{U K C *}=W^{U K R *}=W^{D C *}+\frac{\left(b_{2}+(1+l) v\right)^{2} \delta(1+\delta)^{2} \sigma_{c}^{2}}{2 c_{2 H} c_{2 L} E\left[c_{2}\right](1+2 l)}
$$

\subsubsection{Discretion $(U K N)$}

As above, the problem of optimal RES policy under discretion is solved by backward induction. Taking the investment level in period 1 as well as the firm's reaction function for period 2 in (38) as given, the social planner maximizes state-contingent welfare in period 2:

$$
\begin{array}{r}
W_{2 i}^{U K N}=V_{2}\left(q_{2 i}\right)-C_{2 i}\left(x_{2 i}\right)-L_{2}\left(s_{2 i}, q_{2 i}\right)+B_{2}\left(q_{2 i}\right) \\
+\delta\left[V_{3}\left(q_{3 i}\right)-L_{3}\left(s_{2 i}, q_{3 i}\right)+B_{3}\left(q_{3 i}\right)\right]
\end{array}
$$

The subsequent solution approach is equivalent to that under discretion in the deterministic environment and the setting with uncertain benefits. Substituting (38) into (44), we can derive the welfare-maximizing subsidies in either state as a function of period-1 investment, $s_{2 i}^{U K N}\left(x_{1}\right)$. Inserting these subsidy functions back into (38) gives the optimal investment levels in period 2 as a function of period-1 investment, $x_{2 i}^{U K N}\left(x_{1}\right)$. Using these functional relationships, the firm's first-order condition for optimal investment in period 1 , given in (24), can be adjusted, and one can derive the optimal period-2 subsidy as well as the (state-contingent) investment levels in periods 1 and 2 as functions of the period-1 subsidy, $s_{2 i}^{U K N}\left(s_{1}\right), x_{1}^{U K N}\left(s_{1}\right)$ and $x_{2 i}^{U K N}\left(s_{1}\right)$. Substituting these into the welfare function given in (39) we can identify the welfare-maximizing period-1 subsidy, and subsequently also the other optimal statecontingent subsidy for period 2 :

$$
\begin{gathered}
s_{1}^{U K N *}=s_{1}^{D N *} \\
s_{2 i}^{U K N *}=s_{2}^{D N *}+\frac{\left(E\left[c_{2}\right]-c_{2 i}\right) n_{2}}{n_{1}^{\prime}}
\end{gathered}
$$

with $n_{1}^{\prime}=l^{2} E\left[c_{2}\right] \delta+\mathrm{c}_{1}(1+2 l)^{2}(1+\delta)^{2}>0$, i.e., equivalent to $n_{1}$ used above, except for $c_{2}$ being replaced by $E\left[c_{2}\right]$.

Subsequently, the optimal (state-contingent) investment levels for both periods can be determined:

$$
\begin{gathered}
x_{1}^{U K N *}=x_{1}^{D N *} \\
x_{2 i}^{U K N *}=x_{2}^{D N *}+\frac{\left(E\left[c_{2}\right]-c_{2 i}\right)\left(b_{2}+(1+l) v\right)(1+\delta)}{c_{2 i} E\left[c_{2}\right](1+2 l)}
\end{gathered}
$$

Substituting (45) and (46) into (39) yields optimal welfare in the optimum: 


$$
W^{U K N *}=W^{D N *}+\frac{\left(b_{2}+(1+l) v\right)^{2} \delta(1+\delta)^{2} \sigma_{c}^{2}}{2 c_{2 H} c_{2 L} E\left[c_{2}\right](1+2 l)}
$$

\subsubsection{Comparison of policy scenarios}

We will focus on comparing welfare under unconditional commitment (which also corresponds to the results under rule-based commitment) to that under discretion. Comparing (43) to (47) yields that the welfare differential is identical to that in the deterministic setting:

$$
W^{U K C *}-W^{U K N *}=W^{D C *}-W^{D N *}>0
$$

Contrary to the case with uncertain benefits, unconditional commitment is thus unambiguously superior if investment costs are the source of uncertainty. This is no surprise: in line with the Pigouvian internalization principle, for a society with a given genuine willingness to pay for emission reductions, there need not be any direct effect of the (non-externalized) investment costs on the optimal subsidy rate. So there is no cost from commitment in terms of foregone flexibility to adjust to the new information.

And important caveat to this observation is of course the assumption of linear external benefits of RES deployment. As pointed out above, cost uncertainty may have a second-order effect on the optimal level of the RES subsidy if benefits are non-linear. In this case, there may be a benefit from adjusting the period-2 subsidy to incorporate new knowledge on the actual level of period-2 deployment costs. Consequently, the optimal choice between unconditional commitment and discretion may become ambiguous if benefits are non-linear.

Evidence on the nature of climate policies and their discussion in regions with major renewables support schemes, does, however, not support the assumption of a substantial, genuine, and constant willingness to pay per unit of global emission reduction. Instead, evidence is arguably more in line with the idea of rather externally given quantity targets on emission reductions, or even more specifically a quantity target on renewables deployment, which are to be met through RES subsidies. We turn to this standardprice approach in the following section.

\subsection{Analytical approach: Standard-price case}

We now switch from the Pigouvian approach, in which the social planner implemented the RES subsidy to internalize an external benefit, to the case where the subsidy is instead used with the aim to meet an exogenously set RES deployment target $T$ in period 2 . The planner always commits to a achieving the target as a minimum, but choses whether or not to commit to a particular period-2 subsidy in period 1 . Albeit unlikely a first-best, this standard-price approach seems relevant because it reflects widespread political practice. For example, the EU and many of its Member States have adopted RES deployment targets which shall be achieved by RES policies (European Commission, 2014). Policy-makers may be tempted to pursue a standard-price approach (a) because they typically lack sufficient knowledge about 
the external benefits of RES deployment required to set a Pigouvian subsidy, and (b) simply because, for whichever reasons, the politico-economic environment for climate and energy policy-making is more supportive of the adoption of RES targets. Consequently, the RES target under the standard-priceapproach is unlikely to reflect the deployment level which would emerge under a Pigouvian pricing approach. Moreover, the target needs to be attained irrespectively of the related costs and benefits. We will show that considering this standard-price approach actually reverses the results derived from the Pigouvian setting.

\subsubsection{Unconditional commitment (UKFC)}

If the social planner commits to a single subsidy for period 2, she needs to make sure that the RES deployment target is met even if investment costs in period 2 turn out to be high. Obviously, this also implies that the target will be overshot if period- 2 costs turn out to be low. Consequently, the social planner aims at maximizing welfare given as in (39), subject to the constraint $q_{2 H}=\bar{T}$. Assuming $s_{2 H}=$ $S_{2 L}=S_{2}$, the corresponding Lagrangian writes:

$$
\begin{aligned}
\Lambda^{U K F C}=V_{1}\left(q_{1}\right) & -C_{1}\left(x_{1}\right)-L_{1}\left(s_{1}, q_{1}\right)+B_{1}\left(q_{1}\right) \\
& +E_{i}\left[\delta\left(V_{2}\left(q_{2 i}\right)-C_{2 i}\left(x_{2 i}\right)-L_{2}\left(s_{2}, q_{2 i}\right)+B_{2}\left(q_{2 i}\right)\right)\right. \\
& +\delta^{2}\left(V_{3}\left(q_{3 i}\right)-L_{3}\left(s_{2}, q_{3 i}\right)+B_{3}\left(q_{3 i}\right)\right)+\lambda\left(q_{2 H}-\bar{T}\right)
\end{aligned}
$$

We assume parameters to be such that an interior solution obtains. The firm's reaction functions are identical to those in the Pigouvian setting given in (38). Substituting them into (49), deriving the firstorder conditions for welfare-maximizing subsidies, and solving the resulting equation system yields the optimal subsidy rates:

$$
\begin{aligned}
s_{1}^{U K F C *}=c_{1} \bar{T}- & v(1+\delta)\left(1+\frac{c_{1}}{c_{2 H}}\right) \\
& +\frac{1}{c_{2 H}(1+\delta) n_{3}}\left(\left(c_{1}\right.\right. \\
& \left.+\left(c_{1}+c_{2 H}\right) \delta\right)\left(c_{2 H} v(1+\delta)\left(c_{2 L}(1+l)+\left(c_{2 H}+c_{2 L}-E\left[c_{2}\right]\right) l \delta\right)\right. \\
& \left.\left.-c_{1} c_{2 L}(1+2 l)\left(c_{2 H} \bar{T}-v(1+\delta)\right)\right)\right) \\
s_{2}^{U K F C *}= & \frac{1}{(1+\delta) n_{3}}\left(c_{1} c_{2 L}(1+2 l)\left(c_{2 H} \bar{T}-v(1+\delta)\right)\right. \\
& \left.-c_{2 H} v(1+\delta)\left(\left(c_{2 H}-E\left[c_{2}\right]\right) l \delta+c_{2 L}(1+l(1+\delta))\right)\right)
\end{aligned}
$$

with $n_{3}=(1+2 l)\left(c_{1} c_{2 L}+c_{2 H}\left(c_{2 H}+c_{2 L}-E\left[c_{2}\right]\right) \delta\right)>0$.

Substituting (50) into (38) gives the optimal investment levels: 


$$
\begin{gathered}
x_{1}^{U K F C *}=\frac{1}{n_{3}}\left(\left(c_{2 H}-E\left[c_{2}\right]\right) \delta\left(c_{2 H} \bar{T}(1+2 l)-(1+l) v(1+\delta)\right)\right. \\
\left.+c_{2 L}\left(c_{2 H}(1+2 l) \bar{T} \delta+(1+l) v\left(1-\delta^{2}\right)\right)\right) \\
x_{2 H}^{U K F C *}=\frac{1}{n_{3}}\left(c_{1} c_{2 L}(1+2 l) \bar{T}+(1+l) v(1+\delta)\left(\left(c_{2 H}-E\left[c_{2}\right]\right) \delta-c_{2 L}(1-\delta)\right)\right) \\
x_{2 L}^{U K F C *}=\frac{1}{c_{2 L} n_{3}}\left(c _ { 2 H } \left(c_{1} c_{2 L}(1+2 l) \bar{T}\right.\right. \\
\left.\left.+(1+l) v(1+\delta)\left(\left(c_{2 H}-E\left[c_{2}\right]\right) \delta-c_{2 L}(1-\delta)\right)\right)\right)
\end{gathered}
$$

Substituting (50) and (51) into (39) yields welfare in the optimum:

$$
\begin{aligned}
W^{U K F C *}=\frac{1}{2 c_{2 L} n_{3}} & \left(\left(c_{2 H}-E\left[c_{2}\right]\right)^{2}(1+l)^{2} v^{2} \delta^{2}(1+\delta)^{2}\right. \\
& +c_{2 L}^{2}\left(2\left(c_{1}+c_{2 H}\right)(1+l)(1+2 l) \bar{T} v \delta(1+\delta)-c_{1} c_{2 H} \bar{T}(1+2 l)^{2} \delta\right. \\
& \left.-(1+l)^{2} v^{2}\left(1-\delta^{2}\right)^{2}\right) \\
& +c_{2 L}\left(c_{2 H}\right. \\
& \left.-E\left[c_{2}\right]\right) \delta\left(c_{1}(1+2 l) \bar{T}\left(2(1+l) v(1+\delta)-c_{2 H} \bar{T}(1+2 l)\right)\right. \\
+ & \left.\left.2(1+l) v(1+\delta)\left(c_{2 H} \bar{T}(1+2 l)-(1+l) v\left(1-\delta^{2}\right)\right)\right)\right)
\end{aligned}
$$

\subsubsection{Rule-based commitment (UKFR)/Discretion (UKFN)}

When the social planer aims to determine a state-contingent subsidy rule for period 2 , she needs to make sure the target is met in either state, i.e. $q_{2 i}=\bar{T}$. Considering this constraint jointly with the firm's firstorder conditions given in (38), we derive the state-contingent subsidies for period 2 as a function of the period-1 subsidy:

$$
s_{2 i}^{U K F R}=\frac{c_{2 i}\left(c_{1} \bar{T}+v-s_{1}\right)}{c_{1}+\left(c_{1}+E\left[c_{2}\right]\right) \delta}-v=s_{2 i}^{U K F N}
$$

Thus, by setting the subsidy for period 1 , the social planner automatically commits to the statecontingent subsidies for period 2. This observation also holds under discretion. Even if the social planner can fully adjust the period- 2 subsidy after he has learned about period-1 investments and the actual state of the world, her choice of the state-contingent period-2 subsidy is inevitably predetermined by here choice of the period-1 subsidy as long as the target binds. Thus, with a fixed RES deployment target, the incentive for the policy-maker to behave time-inconsistently actually vanishes. In this case, discretion only generates the benefit to adjust the RES subsidy to the actual state, and therefore is equivalent to rule-based commitment.

Substituting (53) into (39) and deriving the first-order condition for welfare maximization, yields the optimal period-1 subsidy: 


$$
\begin{aligned}
s_{1}^{U K F R *}=s_{1}^{U K F N *} & \\
& =-\frac{1}{(1+\delta) n_{4}}\left(v \delta(1+\delta)(l+\delta(1+l)) E\left[c_{2}\right]\right. \\
& \left.+c_{1}\left(l v(1+\delta)+(1+l) v \delta^{3}+\delta^{2}\left(v(1+l)-\bar{T}(1+2 l) E\left[c_{2}\right]\right)\right)\right)
\end{aligned}
$$

with $n_{4}=(1+2 l)\left(\mathrm{c}_{1}+\mathrm{E}\left[\mathrm{c}_{2}\right] \delta\right)>0$.

Substituting (54) into (53) yields the optimal state-contingent subsidies for period 2:

$$
\begin{aligned}
s_{2 i}^{U K F R *}=s_{2 i}^{U K F N *} & \\
& =\frac{1}{(1+\delta) n_{4}}\left((1+2 l) c_{1}\left(\bar{T} c_{2 i}-v(1+\delta)\right)\right. \\
& \left.-v(1+\delta)\left((1+l)(1-\delta) c_{2 i}+\delta(1+2 l) E\left[c_{2}\right]\right)\right)
\end{aligned}
$$

Substituting (54) and (55) into (38), we derive the optimal (state-contingent) investment levels for both periods:

$$
\begin{gathered}
x_{1}^{U K F R *}=x_{1}^{U K F N *}=\frac{1}{n_{4}}\left(E\left[c_{2}\right](1+2 l) \bar{T} \delta+(1+l) v\left(1-\delta^{2}\right)\right) \\
x_{2 i}^{U K F R *}=x_{2 i}^{U K N *}=\frac{1}{n_{4}}\left(c_{1} \bar{T}(1+2 l)-(1+l) v\left(1-\delta^{2}\right)\right)
\end{gathered}
$$

Inserting (54)-(56) into (39) yields welfare in the optimum:

$$
\begin{aligned}
& W^{U K F R *}=W^{U K F N *} \\
& =\frac{1}{2 n_{4}}\left(2\left(c_{1}+E\left[c_{2}\right]\right)(1+l)(1+2 l) \bar{T} v \delta(1+\delta)\right. \\
& \left.-c_{1} E\left[c_{2}\right] \bar{T}(1+2 l)^{2} \delta-(1+l)^{2} v^{2}\left(1-\delta^{2}\right)^{2}\right)
\end{aligned}
$$

\subsubsection{Comparison of policy scenarios}

Comparing (57) to (52) yields: 


$$
\begin{aligned}
W^{U K F N *}-W^{U K F C *} & \\
& =\frac{(1+2 l)}{2 c_{2 L} n_{3} n_{4}}\left(\left(c_{2 H}\right.\right. \\
& \left.-E\left[c_{2}\right]\right) \delta\left(c _ { 1 } ^ { 2 } c _ { 2 L } ( 1 + 2 l ) \overline { T } \left(\left(c_{2 H}+c_{2 L}\right) \bar{T}(1+2 l)\right.\right. \\
& -2(1+l) v(1+\delta)) \\
& +(1+l)^{2} v^{2}(1+\delta)^{2}\left(\left(c_{2 L}(1-\delta)+E\left[c_{2}\right] \delta\right)^{2}\right. \\
& \left.-c_{2 H}\left(c_{2 L}(1-\delta)^{2}+E\left[c_{2}\right] \delta^{2}\right)\right) \\
& -c_{1}(1+l) v(1+\delta)\left(2 c_{2 L}^{2}(1+2 l) \bar{T}(1-\delta)\right. \\
& -E\left[c_{2}\right](1+l) v \delta(1+\delta) \\
& +c_{2 H}\left(2 c_{2 L}(1+2 l) \bar{T}(1-\delta)+(1+l) v \delta(1+\delta)\right) \\
& \left.\left.\left.+2 c_{2 L}\left(E\left[c_{2}\right](1+2 l) \bar{T} \delta-(1+l) v\left(1-\delta^{2}\right)\right)\right)\right)\right)
\end{aligned}
$$

The solution is complex and not easily interpretable. However, since we know that rule-based commitment is the first-best policy approach and that $W^{U K F R *}=W^{U K F N *}$, it follows that $W^{U K F N *}-$ $W^{U K F C *}>0$. Thus, if the RES subsidy is implemented to attain an exogenously given RES target in period 2, the discretion to adjust the RES subsidy to account for new knowledge on RES deployment costs will always increase welfare.

\subsection{Numerical illustration}

For the case with cost uncertainty, we use the same parameterization as in Table 1, but consider, instead of uncertain benefits, uncertain RES generation costs, with values $c_{2 L}$ and $c_{2 H}$, set such as to vary by ca. $+/-30 \%$ around the costs from the previous section. The probabilities of each state remain $50 \%$. In the case with an explicit (climate) externality benefit, the benefits, $b_{1}$ and $b_{2}$, remain the same as in the deterministic case above. These benefits are, however, replaced with a fixed renewables target, when the policy aim is to guarantee a lower limit of renewables build-out, set to $400 \mathrm{GW}$ of cumulatively installed capacity, just somewhat below the value achieved with the scenarios under benefit uncertainty. Table 4 summarizes the corresponding innovations compared to table 2. Table 5 summarizes the numerical results for our main scenario. 
Table 4: Parameter values assumed for the main scenario with cost uncertainty (all other parameter values as in Table 2).

\begin{tabular}{cccl}
\hline & Value & Unit & Corresponding value in standard unit \\
\hline$c_{1}$ & 0.0082 & $\mathrm{bn} € / \mathrm{GW}^{2}$ & $70 € / \mathrm{MWh}$ levelized capex at $200 \mathrm{GW}$ \\
$c_{2}, E\left[c_{2}\right]$ & 0.0053 & $\mathrm{bn} € / \mathrm{GW}^{2}$ & $45 € / \mathrm{MWh}$ levelized capex at $200 \mathrm{GW}$ \\
$c_{2}^{L}$ & 0.0038 & $\mathrm{bn} € / \mathrm{GW}^{2}$ & $30 € / \mathrm{MWh}$ at $200 \mathrm{GW}$ \\
$c_{2}^{H}$ & 0.0068 & $\mathrm{bn} € / \mathrm{GW}^{2}$ & $60 € / \mathrm{MWh}$ at $200 \mathrm{GW}$ \\
$\beta$ & 0.5 & &
\end{tabular}

\section{Explicit positive externality:}
$b_{1}$
0.92
$\mathrm{bn} € / \mathrm{GW}$
$70 € / \mathrm{tCO} 2$, or $52.5 € / \mathrm{MWh}$
$b_{2}$
$0.92 \mathrm{bn} € / \mathrm{GW}$
$70 € / \mathrm{tCO} 2$, or $52.5 € / \mathrm{MWh}$

\section{Explicit buildout target: \\ $\begin{array}{lll}T & 400 \quad \mathrm{GW}\end{array}$}

Table 5: Results for the main scenario with cost uncertainty

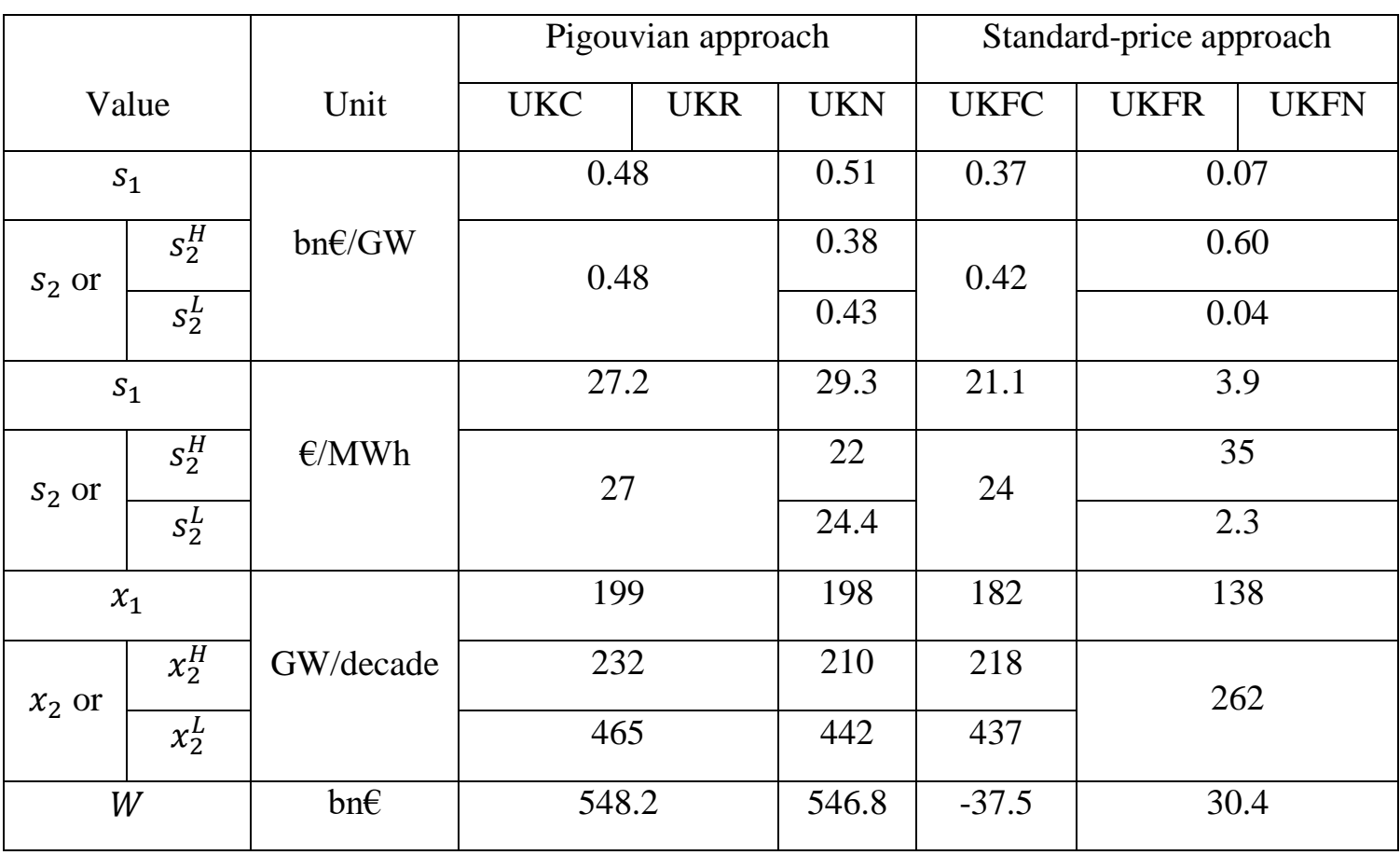

For the Pigouvian setting, our numerical illustration highlights that commitment is only marginally superior to discretion in terms of welfare (commitment increases welfare by $0.2 \%$ ). This confirms once more the finding that with the calibration we have chosen time inconsistency and uncertainty (this time in costs) are only minor issues for optimal policy design - at least under naïve assumptions, i.e. disregarding political arbitrariness and risk aversion. 
For the standard-price setting, our calibration illustrates that discretion outperforms unconditional commitment (in contrast to the Pigouvian setting), and that the welfare difference between both scenarios is more pronounced. The overall smaller (and even negative) welfare levels are due to the fact that the standard-price approach disregards the external benefits of RES deployment.

\section{Discussion}

Overall, our analytical and numerical analyses suggest that if the first-best approach of rule-based commitment is not feasible for RES policies, unconditional commitment should be favored over discretion in many cases - despite forgoing the benefits of being able to adjust RES policies over time. The case for commitment may be further strengthened if several here ignored caveats to discretion are taken into account. Three examples may illustrate this. First, we have assumed technological progress to occur exogenously. However, the costs of period-2 investments may also decrease with increasing period-1 investments due to endogenous learning. In this case, the social loss of underinvestment in period 1 due to RES policy discretion is aggravated. Second, we have neglected that discretion (and rule-based commitment) may bring about significant transaction costs in period 2 . These arise because with every policy revision information needs to be gathered and tedious political bargaining and decision-making processes are required. This again weakens the case for discretion. Third, we disregard issues of political credibility. In fact, the announcement of discretionary decision-making may undermine the credibility of a government more broadly. Private actors may not only draw political decisions related to RES policy into question but also those taken in other policy fields. In this way, discretion in RES policy may create additional costs to society by impairing investments contingent on other public policies.

What lessons from our analysis can be learned for real-world RES policy-making? First of all, it seems fair to assume that the discretionary patterns of RES policies which we observe in many countries (see Figure 1) reduce welfare. Certainly, many RES schemes do provide a certain degree of commitment even though the RES subsidy levels vary from year to year. With some exceptions, subsidy adjustments are not undertaken retrospectively but only for newly installed RES plants. Once the RES plant is set up, operators often received a RES subsidy that is guaranteed for a longer period (e.g., 20 years). Moreover, some upcoming policy adjustments are announced ex ante, e.g., by legally defined degression rates for subsidies, or breathing caps, which adjust a subsidy once a certain deployment threshold is reached. However, none of the mentioned approaches can fully eliminate the threat and impacts of discretionary policy-making. For example, despite a 20-year-payment guarantee, RES investments may still be affected by subsidy variation if the project takes several years to develop, as for offshore wind parks. Similarly, RES subsidy discretion may impair the investment decisions of upstream industries, like RES plant manufacturers and developers. What is more, even if future adjustments are announced by degression rates or breathing caps, there is certainly no guarantee that these adjustment rules remain 
unchanged. If RES policy commitment is warranted, the decisive question thus is how such commitment can actually be created, e.g. by delegating decisions on RES policy design to an independent authority (see, e.g., Brunner et al., 2012; Helm et al., 2003). At the same time, our analysis also implies that RES policy adjustments must not be ruled out in all circumstances. If the benefits of discretion are high (because uncertainty about external benefits of RES deployment is expected to decline significantly in due time) and costs of discretion are low (for example, because an independent authority reduces the threat of arbitrary policy-making), allowing future RES policy adjustments may make sense. Similarly, we have shown that if policy makers can credibly commit to a future RES deployment target and the costs of attaining this target are uncertain, it may by reasonable to allow for adjusting the RES subsidy to attain the target at least cost.

Our relatively simple modeling is subject to certain constraints. Our partial equilibrium framework focusing on RES investments ignores impacts of RES policy commitment and discretion in the nonrenewable power sector and beyond the power sector. For example, discretion in RES policy may also result in irreversible long-term investments being inefficiently shifted from the RES to the nonrenewable power sector, thus producing additional social costs. In addition, our analysis could be refined with a continuous probability function for future states (rather than our two discrete states). This could allow investigating intermediate solutions between unconditional commitment and discretion, i.e., where the social planner commits to a limited number of discrete state-contingent RES subsidy paths which allow only an imperfect mapping of the continuous range of possible states (unconditional commitment to only one subsidy rate is an extreme case of this approach). Yet, we would expect that this refinement will primarily affect the size, not the sign, of the welfare differential between commitment and discretion. Similarly, a more elaborate analysis could apply a continuous time model (instead of our discrete time model with three periods). While we do not expect that this changes the trade-off between commitment and discretion fundamentally, it may allow addressing additional interesting research questions, such as the optimal length of commitment in the presence of uncertain benefits and costs.

These constraints notwithstanding, our model provides insights for optimal RES policy making and climate policy more generally. Policy makers face challenges similar to those highlighted here when implementing carbon prices. On the one hand, a credible long-term price signal is required to make private actors invest into carbon abatement. On the other hand, the benefits and costs of carbon abatement are still highly uncertain. This trade-off will become more relevant for policy making once the level of ambition of existing climate policies, such as the EU Emissions Trading Scheme, has risen significantly. Nevertheless, the welfare differentials between our policy scenarios are generally rather small. This suggests that choosing an adequate ambition for climate policy today is more important than the way policy makers commit to it across time. 


\section{Conclusion}

Adequate levels of private investment prerequisite stable political frameworks, and this is especially important for long-lived infrastructure investments. The corresponding paradigm of long-term political stability and policy commitment can, however, be challenged if benefits and costs of policies are so uncertain ex ante that failure to revise policies when new information becomes available has itself large costs. There is thus a trade-off between policy commitment encouraging investment and discretion allowing to update policies in future in line with new information. Our analysis focuses on a policy domain where this trade-off seems significant: climate change mitigation by RES energy support policies. Large scale RES investments and deployment are only viable with some clarity about the medium-term evolution of policy support. However, uncertainty on the social cost of carbon and RES deployment costs equally mean it cannot be excluded that policies agreed today warrant adjustments in a few years when new information becomes available.

In a dynamic partial equilibrium framework that can account for political opportunism, climate or technology uncertainty, and risk aversion, committing to a policy path with pre-defined adjustments to new information is found to be welfare-maximizing. Politically contracting such contingencies in detail seems implausible for the case of climate policy, and instead a simpler commitment to a fixed policy path, or - on the other extreme - discretion to freely adjust future policy to new information, seem more realistic. Analytically, the choice between the latter two strategies is ambiguous: Depending on parameters, either of the two can yield higher welfare. In a naïve numerical application, calibrated roughly to a case of subsidies for wind turbine deployment, the benefit of adjusting future subsidies to the originally imprecisely estimated real climate damages dominates commitment, so that discretion appears beneficial.

However, this apparent advantage of discretion over commitment disappears under more realistic assumptions. The slowness by which climate uncertainty resolves over time, idiosyncratic deviations of future policy decisions from current preferences, and risk aversion strengthen the case for commitment.

If the major source of uncertainty is technology costs rather than climate benefits, the case for or against commitment is influenced by whether the political aim is really to contain climate change or to achieve a fixed renewables deployment target at least cost. In the latter case, we see that discretion appears more favorable if the requirement to achieve a strict target restricts political opportunism.

The identified situations where welfare achieved under discretion exceeds welfare under policy commitment challenges the traditional wisdom that environmental policy makers should always seek to provide stable framework conditions, even if we do find that in the most realistic cases of our example, commitment seems to indeed increase welfare. Overall, the welfare differences we find are often significant but limited to a few percent of the absolute overall system benefits of the renewables 
considered. Despite the importance of time-consistency and uncertainty issues, choosing the right order of magnitude of support may thus be more important than the exact way the support is committed to. 


\section{References}

Abrego, L., Perroni, C., 2002. Investment subsidies and time-consistent environmental policy. Oxford Economic Papers 54, 617-635.

Acemoglu, D., Aghion, P., Bursztyn, L., Hemous, D., 2012. The Environment and Directed Technical Change. Amer. Econ. Rev. 102, 131-166.

Aghion, P., David, P.A., Foray, D., 2009. Science, technology and innovation for economic growth: Linking policy research and practice in 'STIG Systems'. Research Policy 38, 681-693.

Baldursson, F., von der Fehr, N.-H., 2008. Prices vs. quantities: Public finance and the choice of regulatory instruments. European Economic Review 52, 1242-1255.

Bennear, L.S., Stavins, R.N., 2007. Second-Best Theory and the Use of Multiple Policy Instruments. Environ. Resource Econ. 37, 111-129.

Biglaiser, G., Horowitz, J.K., Quiggin, J., 1995. Dynamic pollution regulation. J. Regul. Econ. 8, 33-44.

Brunner, S., Flachsland, C., Marschinski, R., 2012. Credible commitment in carbon policy. Climate Policy 12, 255-271.

Denholm, P., Margolis, R., 2008. Supply Curves for Rooftop Solar PV-Generated Electricity for the United States, Technical Report NREL/TP-6A0-44073. National Renewable Energy Laboratory (NREL), Golden, CO.

European Commission, 2014. Communication from the Commission to the European Parliament, the Council, the European Economic and Social Committee and the Committee of the regions: A policy framework for climate and energy in the period from 2020 to 2030. COM(2014) 15 final. European Commission, Brussels.

Finon, D., Perez, Y., 2007. The social efficiency of instruments of promotion of renewable energies: A transaction-cost perspective. Ecol. Econ. 62, 77-92.

Fischer, C., Newell, R.G., 2008. Environmental and Technology Policies for Climate Change Mitigation. J. Environ. Econ. Manage. 55, 142-162.

Fischer, C., Preonas, L., 2010. Combining Policies for Renewable Energy: Is the Whole Less Than the Sum of Its Parts? International Review of Environmental and Resource Economics 4, 51-92. 
Fisher, S., 1977. Long-Term Contracts, Rational Expectations, and the Optimal Money Supply Rule. J. Polit. Econ. 85, 191-206.

Foxon, T., Pearson, P., 2008. Overcoming barriers to innovation and diffusion of cleaner technologies: some features of a sustainable innovation policy regime. Journal of Cleaner Production 16, S148-S161.

Goulder, L.H., Schneider, S.H., 1999. Induced Technological Change and the Attractiveness of $\mathrm{CO}_{2}$ Emissions Abatement Policies. Resour. Energy Econ. 21, 211-253.

Greenstone, M., Kopits, E., Wolverton, A., 2013. Developing a Social Cost of Carbon for US Regulatory Analysis: A Methodology and Interpretation. Review of Environmental Economics and Policy 7, 23-46.

Helm, D., Hepburn, C., Mash, R., 2003. Credible Carbon Policy. Oxford Rev. Econ. Pol. 19, 438-450.

Helm, D., Hepburn, C., Mash, R., 2004. Time Inconsistent Environmental Policy and Optimal Delegation, Department of Economics Discussion Paper 175. Oxford University, Oxford, UK.

Hepburn, C., 2006. Regulation by Prices, Quantities, or both: A Review of Instrument choice. Oxford Rev. Econ. Pol. 22, 226-247.

Hirth, L., 2013. The Market Value of Variable Renewables. Energ. Econ. 38, 218-236.

IEA, 2015. World Energy Outlook 2015. International Energy Agency (IEA), Paris.

Jacoby, H.D., Ellerman, A.D., 2004. The Safety Valve and Climate Policy. Energ. Policy 32, 481-491.

Kalkuhl, M., Edenhofer, O., Lessmann, K., 2012. Learning or Lock-in: Optimal Technology Policies to Support Mitigation. Resour. Energy Econ. 34, 1-23.

Kelly, D.L., Kolstad, C.D., 1999. Bayesian learning, growth, and pollution. Journal of Economic Analysis and Control 23, 491-518.

Kelly, D.L., Tan, Z., 2015. Learning and climate feedbacks: Optimal climate insurance and fat tails. J. Environ. Econ. Manage. 72, 98-122.

Kitzing, L., Mitchell, C., Morthorst, P.E., 2012. Renewable energy policies in Europe: converging or diverging? . Energ. Policy 51, 192-201.

Kline, D., Heimiller, D., Cowlin, S., 2008. A GIS Method for Developing Wind Supply Curves, Technical Report NREL/TP-670-43053. National Renewable Energy Laboratory (NREL), Golden, CO. 
Kydland, F., Prescott, E., 1977. Rules rather than discretion: The inconsistency of optimal plans. J. Polit. Econ. 85, 473-492.

Lehmann, P., Gawel, E., 2013. Why should support schemes for renewable electricity complement the EU emissions trading scheme? Energ. Policy 52, 597-607.

Levine, P., Stern, J., Trillas, F., 2005. Utility price regulation and time inconsistency: comparisons with monetary policy. Oxford Economic Papers 57, 447-478.

Lohmann, S., 1992. The Optimal Degree of Commitment: Credibility versus Flexibility. Amer. Econ. Rev. 82, 273-286.

Marsiliani, L., Renström, T.I., 2000. Time Inconsistency in Environmental Policy: Tax Earmarking as a Commitment Solution. The Economic Journal 110, 123-138.

Neuhoff, K., 2005. Large-scale deployment of renewables for electricity generation. Oxford Rev. Econ. Pol. 21, 88-110.

Palmer, K., Burtraw, D., 2005. Cost-effectiveness of renewable electricity policies. Energ. Econ. 27, 873-894.

Pindyck, R.S., 2000. Irreversibilities and the timing of environmental policy. Resour. Energy Econ. 22, 233-259.

Pindyck, R.S., 2002. Optimal timing problems in environmental economics. Journal of Economic Dynamics and Control 26, 1677-1697.

Pizer, W.A., 2002. Combining price and quantity controls to mitigate global climate change. J. Public Econ. 85, 409-434.

Purkus, A., Röder, M., Gawel, E., Thrän, D., Thornley, P., 2015. Handling uncertainty in bioenergy policy design - A case study analysis of UK and German bioelectricity policy instruments. Biomass and Bioenergy 79, 64-79.

REN21, 2016. Renewables 2016: Global Status Report. Renewable Energy Policy Network for the 21st Century (REN21) Secretariat, Paris.

Roberts, J., Spence, M., 1976. Effluent charges and licenses under uncertainty. J. Public Econ. 5, 193208.

Rodrik, D., 2014. Green industrial policy. Oxford Rev. Econ. Pol. 30, 469-491. 
Roe, G.H., Baker, M.B., 2007. Why Is Climate Sensitivity So Unpredictable? Science 318, 629-632.

Rogoff, K., 1985. The Optimal Degree of Commitment to an Intermediate Monetary Target. Quarterly Journal of Economics 100, 1169-1189.

Rubin, E.S., Azevedo, I.M.L., Jaramillo, P., Yeh, S., 2015. A review of learning rates for electricity supply technologies. Energ. Policy 86, 198-218.

Stavins, R.N., 1996. Correlated uncertainty and policy instrument choice. J. Environ. Econ. Manage. $11,218-232$.

Tol, R.S.J., 2009. The Economic Effects of Climate Change. Journal of Economic Perspectives 23, 2951.

Ulph, A., Ulph, D., 2013. Optimal Climate Change Policies When Governments Cannot Commit. Environ. Resource Econ. 56, 161-176.

Weitzman, M.L., 1974. Prices vs. quantities. Rev. Econ. Stud. 41, 477-491. 